\title{
Structural behaviour of prefabricated Stressed-Skin Engineered Timber Composite Flooring Systems
}

\author{
Kristopher Orlowski ${ }^{{ }^{*},}$, Shanaka Kristombu Baduge ${ }^{a}$, Priyan Mendis ${ }^{a}$, Yusak Oktavianus ${ }^{a}$ \\ ${ }^{a}$ Department of Infrastructure Engineering, The University of Melbourne, VIC 3052, Australia \\ *kristopher.orlowski@unimelb.edu.au
}

\begin{abstract}
The primary focus of this study is understanding the behaviour and structural performance of prefabricated composite timber floor cassette systems with Oriented strand board (OSB) stressed-skins. These do not have a dedicated top flange, instead their plywood webs are integrally bonded to the OSB flooring skin through a chemical connection. Subsequently, local buckling of the stressed-skin was found to occur as the first failure mode. Specimens with $150 \mathrm{~mm}$ and $300 \mathrm{~mm}$ nail spacings were investigated for its effects on performance due to the criticality of the integrated web to floor skin connection in these systems. A total of 20 stressed-skin specimens were tested in three-point bending with recordings of the applied force, displacement, slip and failure modes. It was found that local buckling of the skin is prone to occur prior to reaching the designed SLS limit. A detailed Finite Element Analysis (FEA) which takes into consideration the full behaviour of the materials and the glue and nail connections along with failure modes has been validated and used to provide insight to potential design solutions. Key parameters investigated include the adhesive properties, the ratio of clear effective outstand width of the flange to the thickness of the stressed-skin $\left(b_{\text {eff,o }} / t\right)$, ratio of the clear depth of the web to the thickness of the web $\left(d_{p} / t_{w}\right)$, ratio of the clear span to the total depth of the composite beam $\left(L_{c} / D\right)$ and finally the spacing of the nails. This has resulted in a broad level understanding of the effects of these design parameters to the behaviour of stressed-skin engineered timber flooring cassettes.
\end{abstract}

Keywords: Stressed-skin; Timber flooring cassette; Engineered wood products (EWP); Three-point bending; Oriented strand board (OSB); Prefabricated; Finite element analysis (FEA).

\section{Introduction}

Prefabrication is a growing method of modern construction that has vast opportunities in the fields of automation and advance manufacturing which are being refined and improved upon to better compete against traditional methods of construction. This is particularly in terms of cost competitiveness, quality of work, flexibility of design and sustainability [1-3]. Prefabrication is a suitable platform to adopt novel and efficient materials as well as to develop an optimum combination of several materials to form components of larger systems. One such material type and system which is focused upon in this research are engineered timber-based flooring systems which are suitable for Design for Manufacturing and Assembly (DfMA) and offsite construction. Engineered Wood Products (EWPs) are increasingly being developed and used for the prefabricated building 
industry as a more versatile and better performing solution compared to conventional solid sawn-cut wood and other construction materials [4]. Engineered timber I-beams have been relatively well studied in many areas such as flexural behaviour [5], bearing capacity [6], torsional rigidity [7], composite use of materials [8], shear behaviour [9], span and design guidelines [10] and behaviour with web openings [11]. Even there are standards such as ASTM - D5055 which have been developed to provide a 'Standard Specification for Establishing and Monitoring Structural Capacities of Prefabricated Wood I-Joists' [12]. EWPs have been well studied and their behaviour has been well understood. However, there is a lack of work in the effective combination of types of EWPs used together as a composite system and their further refinement. Engineered timber I-beams have a top and bottom flange with a web in-between. When adapted to prefabrication in the form of cassettes then they are also connected with rimboard along the outside edge to prevent overturning as shown in Figure 1 [13].

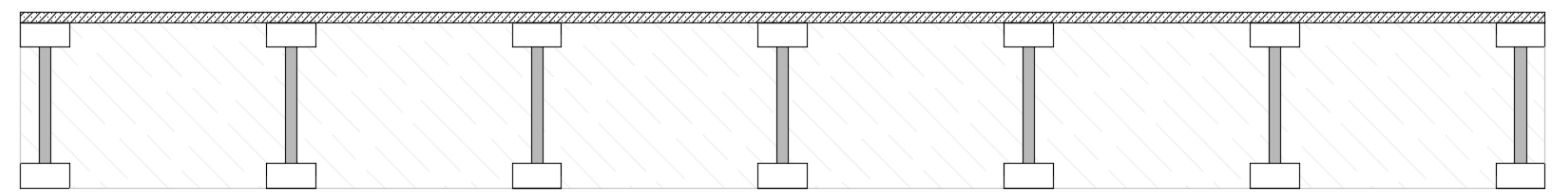

(a)

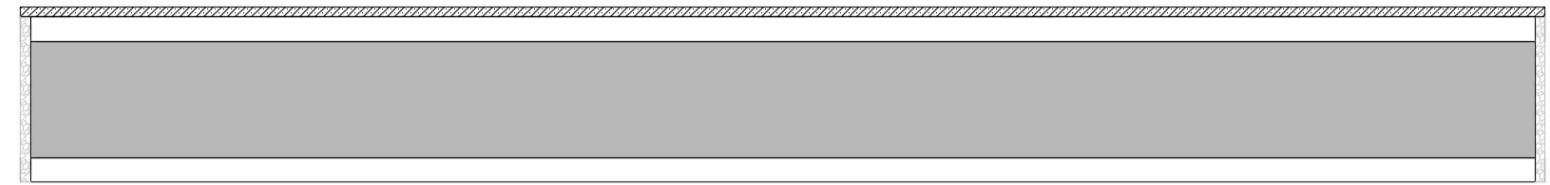

(b)

Figure 1. Traditional engineered timber flooring cassette with I-Beam joists: (a) Cross-section view; (b) Profile view

This study forwards the use of reductive design to potentially further refine these systems. Reductive design as a philosophy builds on the principles of minimalism and removal of the non-essential through the minimisation of the number of components [14-16]. For this project this concept was applied to traditional engineering timber floor systems by the removal of the top flange since the web is now to be directly and integrally bonded to the skin/sheathing as shown in Figure 2. By gluing the floor skin to the joist, a stressed-skin timber flooring solution where the flooring sheet carries load through composite action is achieved [17]. This was practically achieved due to prefabrication and controlled manufacturing methods which allowed both a glued and nailed connection to be repeatedly and reliably made rather than a nailed only connection.

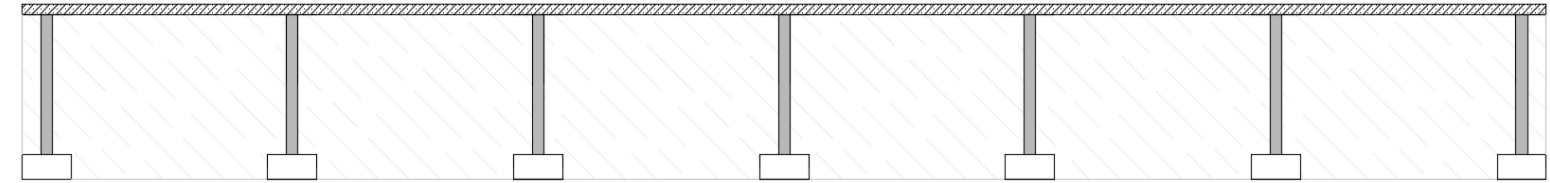

(a)

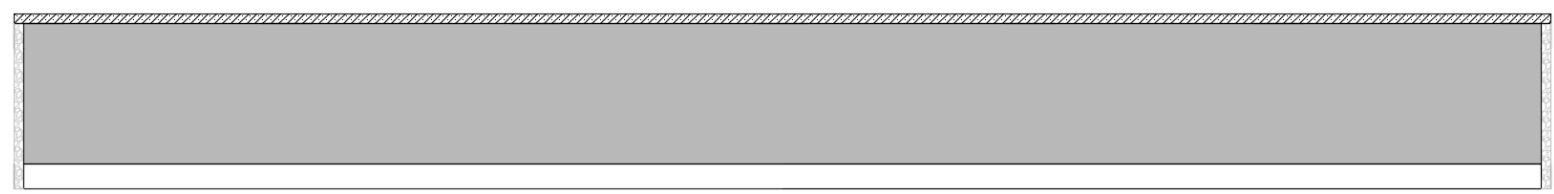

(b) 
Figure 2. Stressed-skin flooring cassette with removal of top flange: (a) Cross-section view; (b) Profile view

Reductive design does not only reduces the number of components and offers 'pure aesthetic' [14] but it has vast practical advantages beyond direct cost savings. These are centred around prefabrication and thus are exploited in the proposed system. For example, manufacturing complexity decreases, supply chain and inventory is smaller and general management and quality assurance processes also become simpler. However, reducing complexity may limit technical functionality and performance. It has been discovered in early investigations of stressed-skin action that for joist spacings of $450 \mathrm{~mm}$ to $600 \mathrm{~mm}$ that between $62 \%$ and $83 \%$ of the floor panelling/sheathing acted in composite with the joists [18]. Therefore, full composite behaviour may not occur. Additionally, the spacing and the shear effects in the floor under compression results in less than full usage of the sheathing [19]. However, there is potential for floor skins to act in the same function as a top flange of a regular I-beam. Plywood (PLY) has been investigated as the skin material in the past [19-21], although since then Oriented Strand Board (OSB) has taken over many markets as it sources underutilised softwood species and is notably cheaper [22]. Some early work has been carried out in the investigation of creep in these OSB skinned systems [23], design equations for shear and flexural deflection under point load [24] and local buckling of OSB without perpendicular stiffening [25]. However, there is little to no research observing the use of OSB in stressed-skin flooring cassettes or on the structural analysis and improved design thereof.

In summary, the hypothesis is that if the top flange is removed and the flooring panel is adequately bonded through both adhesive and nails to the joists then the floor panel/sheathing can essentially act as the top flange of the joist. That is, it may take in-span compressive loads and hence become a stressed-skin. In this way, stressed-skin systems may be prone to local buckling prior to reaching serviceability and ultimate capacity limits. Thus, this investigation delves into the understanding of the force-deflection behaviour, failure modes and configuration adjustments in prefabricated stressed-skin floors which do not have a separate dedicated top flange in contrast to traditional flooring cassettes which do.

\section{Experimental program}

\subsection{Specimen design}

The prefabricated cassettes as shown prior in Figure 2 have been manufactured with a jig to tolerances of $5 \mathrm{~mm}$ and then cut into beam-like configurations according to their tributary width. This is shown in Figure 3 along with the respective material allocation and dimensions. The selection of the materials has been based on the merits of readily available EWPs to aid in providing material and cost efficiency. The length of the specimens is only $2400 \mathrm{~mm}$. This short span design makes this system particularly suitable for high volume use corridors where shear forces may be a concern, hence the solid web design. The depth is fixed at $300 \mathrm{~mm}$ to be within typical structural depth of floors for mid-rise construction so as to allow for services and acoustic breaks between levels [26]. An overview of the arrangement of the structural members and the selected materials are shown in Figure 3. The corresponding product details are summarised in Table 1, this includes their strength class with respect to the relevant building standards and manufacturers product declarations [27-30]. 


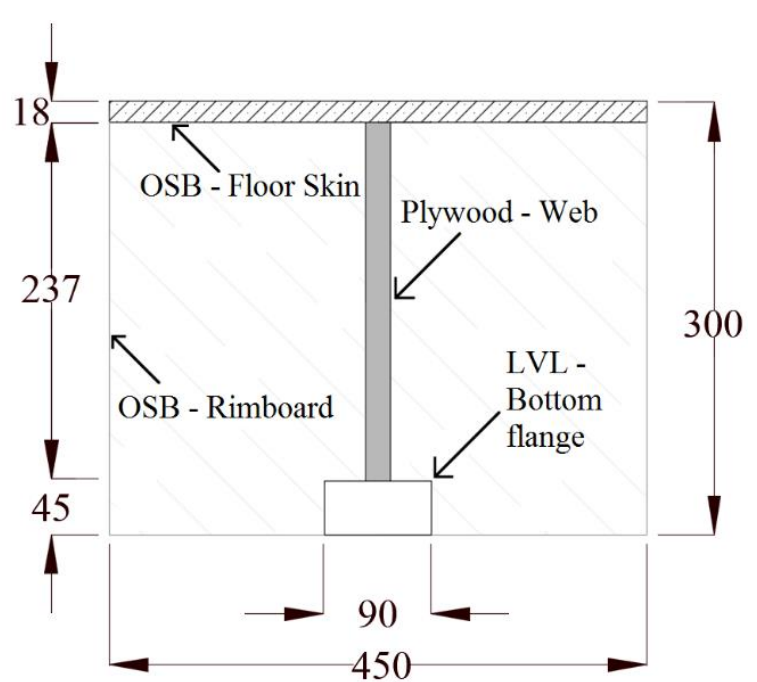

(a)

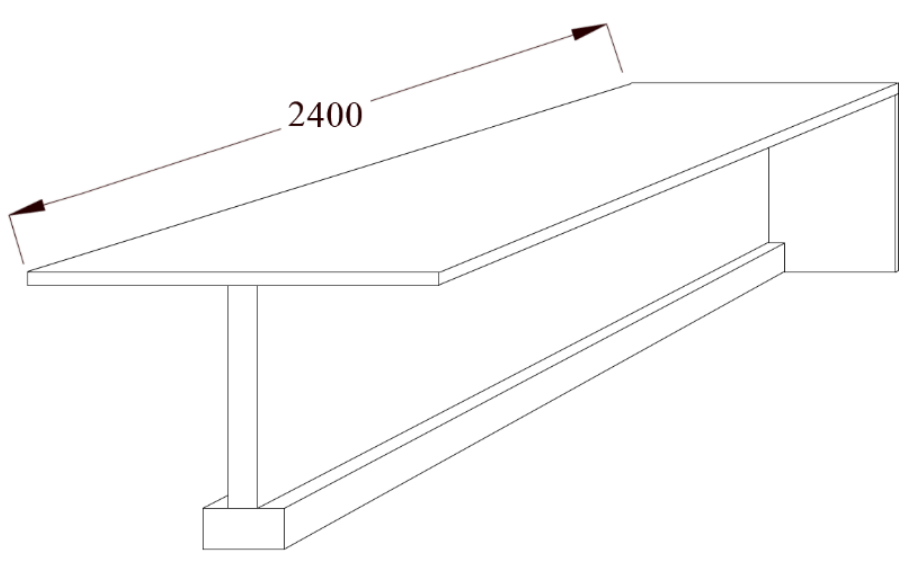

(b)

Figure 3. Composite stressed-skin timber flooring specimen design; (a) Material assignment and crosssection geometry, units $\mathrm{mm}$; (b) Three-dimensional perspective drawing with front rimboard removed.

Table 1. Engineered material used summary.

\begin{tabular}{|c|c|c|c|c|c|}
\hline Material & Location & Cross section dimension (mm) & Product Name & $\begin{array}{l}\text { Strength } \\
\text { Class }\end{array}$ & $\begin{array}{c}\text { Densities } \\
\left(\mathrm{kg} / \mathrm{m}^{3}\right)\end{array}$ \\
\hline OSB & Skin and Rimboard & $\begin{array}{c}18 \times 450 \text { (Skin) } \\
300 \times 450 \text { (Rimboard) }\end{array}$ & $\begin{array}{c}\text { EGGER OSB } 4 \\
\text { TOP }\end{array}$ & OSB 4 & $620^{*}$ \\
\hline PLY & Web & $21 \times 237$ & CHH Ecoply & F11 & 550 \\
\hline LVL & Bottom flange & $45 \times 90$ & CHH hySPAN & F14 & 580 \\
\hline
\end{tabular}

An $18 \mathrm{~mm}$ Oriented Strand Board (OSB) panel flooring was chosen to act as the stressed-skin. This was oriented with the stronger span positioned to bridge the distance between the joists. The thickness of this panel was based on traditional timber I-beam flooring systems where it is governed by the spanning capability from joist to joist. This distance was set at $450 \mathrm{~mm}$, since it is by far the most common joist to joist distance in practice as it is governed such that it matches the spacing of timber studs in timber wall frame construction [31]. This enables loads to be transferred between structural components most directly [31]. A $21 \mathrm{~mm}$ F11 plywood panel has been chosen for the web as it is particularly good in resisting shear forces due to its orthogonally layered build-up. A bottom flange has been incorporated to the underside of the web to carry the tensile forces when the floor bends under vertical loading. By far the most appropriate EWP to undertake this role is a Laminated Veneer Lumber (LVL) stud. This is due to the parallel laminated veneers providing the greatest amount of in-span strength and stiffness without the high variation of irregularities and imperfections that comes with solid sawn-cut sections. In this application, a standard 90x45 mm LVL section was chosen for its availability and cost efficiency per given cross-section size. Rimboards are used around the perimeter of the prefabricated cassette to hold the joists upright under lateral load. OSB was chosen for this application since this isn't the primary loading direction, additionally, consistency of materials makes use of the expected offcut from the flooring skin during prefabrication. Each of the joins have polyurethane (PU) adhesive (Sika-221) due to its standard and proven use in timber construction. Additionally, a $3 \mathrm{~mm}$ diameter ring shank nails at lengths such that they are embedded at least $30 \mathrm{~mm}$ into the web are used throughout to aid in providing strength to each connection. 
Overall, 20 floor specimens of $150 \mathrm{~mm}$ and $300 \mathrm{~mm}$ nail spacings with the glued connections have been chosen for experimental investigation due to the common nature and cost efficiency of these nail spacings. The twodifferent nail spacing were tested so as to accurately determine its influences on structural performance which needs to be balanced with time and cost in manufacturing for prefabrication. Influences are due to its own effect on increase in the strength of the connection through closer nail spacings providing a more uniform pressure and stronger hold for the glue during its curing thus improving the connection strength and overall performance.

\subsection{Material properties}

Representative specimens have been tested in accordance with the Australian and New Zealand standards and compared to the manufactures documentation along with previous research to obtain the full set of mechanical properties to be used for the finite element analysis [29]. The values from the manufacturer and the Australian and New Zealand standards were cross checked with those which have been previously studied [32-35]. The various materials elastic constants and properties used in the finite element modelling for this research are summarised in Table 2 and Table 3 [36-38].

Table 2. Material properties used of each component.

\begin{tabular}{|c|c|c|c|c|c|c|c|c|c|c|}
\hline EWP & $\begin{array}{c}\text { Density } \\
\left(\mathbf{k g} / \mathbf{m}^{\mathbf{3}}\right)\end{array}$ & $\begin{array}{c}\text { E1 } \\
(\mathbf{M P a})\end{array}$ & $\begin{array}{c}\text { E2 } \\
(\mathbf{M P a})\end{array}$ & $\begin{array}{c}\text { E3 } \\
(\mathbf{M P a})\end{array}$ & $\mathbf{\text { Nu12}}$ & $\mathbf{\text { Nu13 }}$ & $\mathbf{\text { Nu23 }}$ & $\begin{array}{c}\text { G12 } \\
(\mathbf{M P a})\end{array}$ & $\begin{array}{c}\text { G13 } \\
(\mathbf{M P a})\end{array}$ & $\begin{array}{c}\text { G23 } \\
(\mathbf{M P a})\end{array}$ \\
\hline Ply & 550 & 10500 & 10500 & 1300 & 0.264 & 0.365 & 0.365 & 680 & 125 & 125 \\
\hline LVL & 580 & 13200 & 500 & 280 & 0.34 & 0.37 & 0.41 & 660 & 550 & 100 \\
\hline OSB & 620 & 4100 & 2950 & 3450 & 0.31 & 0.32 & 0.34 & 1370 & 1250 & 130 \\
\hline
\end{tabular}

Table 3. Web strength properties used.

\begin{tabular}{cc|}
\hline Strength Category & Value (MPa) \\
\hline Bending & 31.0 \\
Tensile & 18.0 \\
Panel Shear & 4.5 \\
Rolling Shear & 1.8 \\
Compression in plane & 22.0 \\
Compression normal to the plane & 12.0 \\
Modulus of Elasticity & 10,500 \\
Modulus of Rigidity & 525 \\
\hline
\end{tabular}

To appropriately predict the stiffness and strength of the polyurethane adhesive used, a number of small-scale tests have been set up and carried out. The force - displacement graphs generated from the tests allowed the determination of the fracture energy parameter used as a key input to the finite element analysis. An adhesive with the commercial name of Sika 221 [39] which is a one-component polyurethane was used to adhere the plywood web to the skin, rimboard and bottom LVL. The connection specimens were prepared by first adhering the glue on large samples of each respective timber at a minimal thickness with the appropriate ring shank nail spacings of $150 \mathrm{~mm}$ and $300 \mathrm{~mm}$ being the only pressure force applied to mimic manufacturing conditions. The curing period of 2 hours was taken before smaller specimens were cut out for testing in the laboratory. Block shear tests were performed 24 hours later on cut out block sections of dimension of $45 \mathrm{~mm}$ by $45 \mathrm{~mm}$ in full accordance to the Australian Standard 4364: 'Timber - Bond performance of structural adhesives' at a loading late of $12.8 \mathrm{~mm} / \mathrm{min}$ [40]. These specimens came from locations close and far from the nailing locations to 
determine its average properties. The outcomes of these tests were that the glue used in this manner has a shear strength $\left(f_{s, g}\right)$ of $1.77 \mathrm{MPa}$. The polyurethane adhesive in typical manufacturing conditions has shown lower properties in shear and axial tension when compared to the ideal values in perfect conditions which are presented by the manufacturer in their corresponding technical note [39]. The experiments on the glued connections showed their capacity having a standard deviation of $0.6 \mathrm{MPa}$, this may be due to the realistic manufacturing conditions in place when applying and pressing the glue bond, thus there may be variation in the glueline thickness and spread, the applied pressure and the cleanliness of the surfaces. The stiffness or the young's modulus $(E)$ of the glue was found to be on average $7.8 \mathrm{MPa}$ and the corresponding average value of the fracture energy $\left(G_{f}\right)$ was found to be $0.9 \mathrm{MPa}$.

\subsection{Experiment setup}

A three-point bending test similar to the beam shear strength test in Clause 2.7 from AS4063.1 was used to investigate the performance of cut sections of the novel engineered timber flooring cassettes [37]. The top skin is restrained from unintended lateral movement but allowed to deflect freely in the direction of loading. The length (which is 8 times the depth) conforms to typical transport and lifting limitations [41] as well as to AS4063. Additionally, the span is such that the pin and roller support are located at a distance equivalent to the depth of the section within each end of the floor. This results in a clear span of $1800 \mathrm{~mm}$ for this configuration. Mid-span loaded at such span to depth ratios potentially induce a rolling shear failure in the web/flange joint and/or in the web material itself. The testing of the specimens were carried out in accordance to the Australian Standards 4063.1 Characterisation of structural timber - Test methods [37]. The test is originally designed for shear strength determination through the use of a constant displacement-controlled three-point bending test configuration with key requirements of a span to depth ratio of 6 and rounded steel bearing plate supports. The testing configuration for the of the stressed-skin floor specimens is shown in Figure 4.

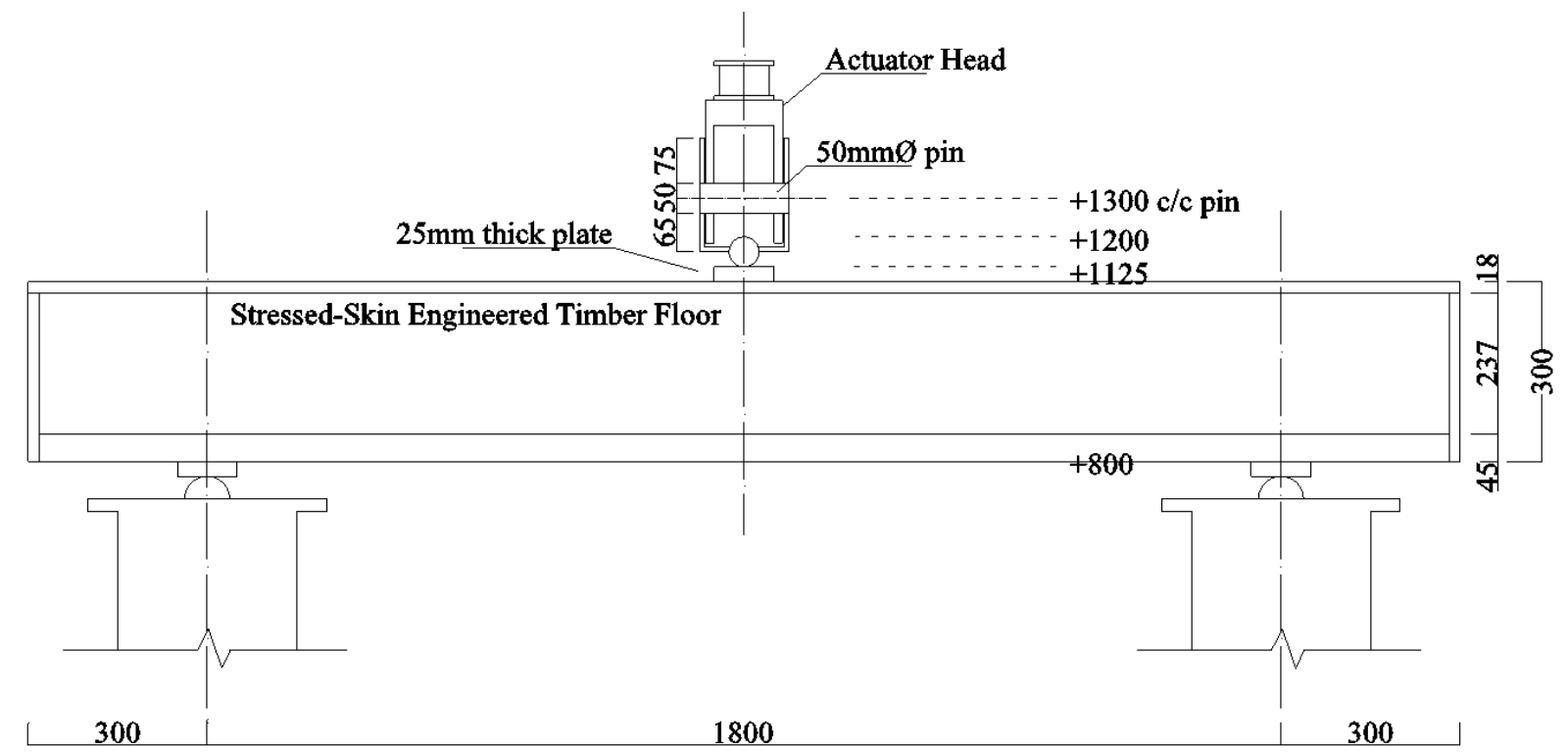

(a) 


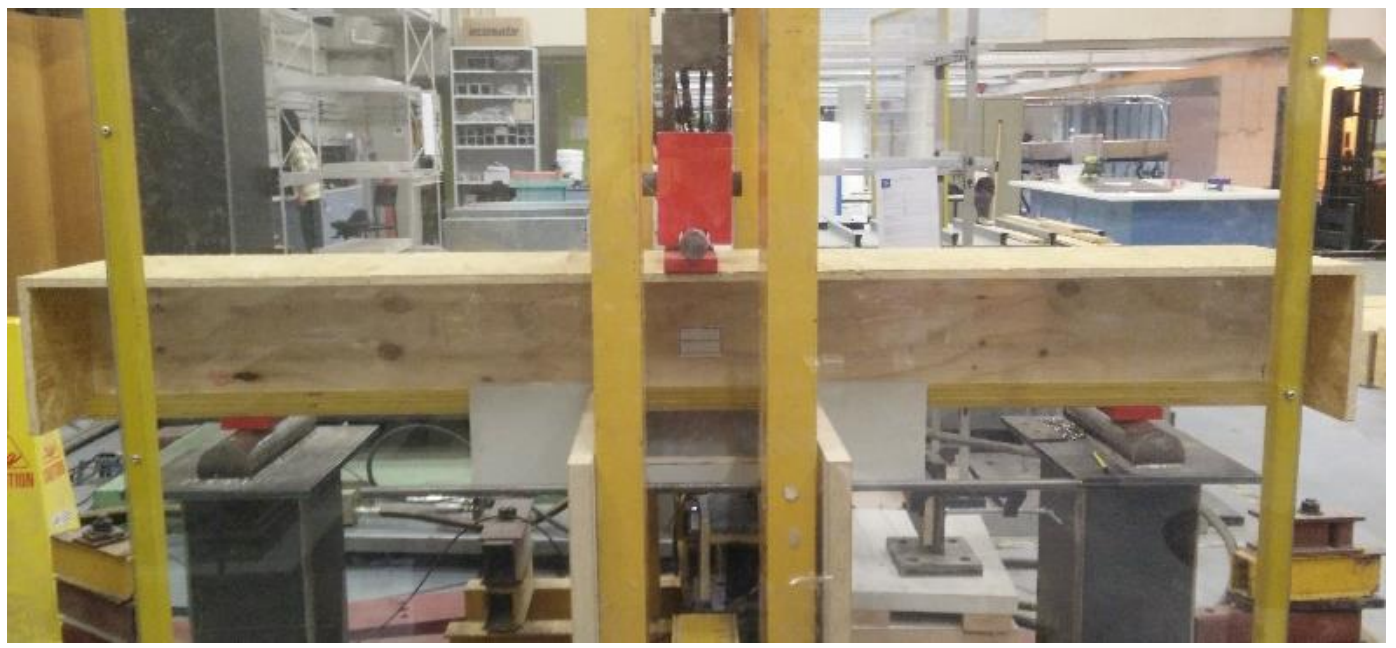

(b)

Figure 4. Load configuration and specimen dimensions used in the experimental program: (a) Plan (in $\mathrm{mm}$ ); (b) Photograph.

\subsection{Instrumentation and Testing}

A graduate displacement rate of $2 \mathrm{~mm} / \mathrm{min}$ was applied to ensure that there was negligible dynamic effect [42]. Steel plates were used on top of rollers to spread the load so that no concentrated damage effects were present. A Material Test Systems (MTS) hydraulic actuator and load cell was used at centre span which has an axial force capacity of $500 \mathrm{kN}$. This is to an accuracy in force and displacement of $0.01 \mathrm{kN}$ and $0.01 \mathrm{~mm}$ respectively. The force on the load cell and displacement of the actuator head was measured for each of the 20 specimens axially by using a Campbell Scientific CR800 Series data logger every 0.01 seconds [43]. Additionally, laser triangulation sensors with a precision of $0.01 \mathrm{~mm}$ were installed on the ground measuring up to the underside of the beam at quarter span and centre span to capture the deflection at various locations over time. Further to this, laser sensors were also mounted on the web to LVL interface to capture the slip movement of the bottom flange relative to the web.

\section{Test results and discussion}

\subsection{Primary failure modes and analysis}

Three major modes of failure were observed and recorded for the $150 \mathrm{~mm}$ and $300 \mathrm{~mm}$ nails spacing specimens as shown in Table 4. These were then superimposed onto the later presented force - displacement graphs. The purpose of the failure mode analysis is that they can be individually understood and addressed by changing the appropriate parameters to delay the onset and the severity of each respected mode of failure.

Table 4. Failure mode summary.

\begin{tabular}{|c|c|c|c|c|c|}
\hline \multirow{2}{*}{$\begin{array}{c}\text { Failure } \\
\text { mode }\end{array}$} & \multirow[t]{2}{*}{ Failure type } & \multicolumn{2}{|c|}{ 150NS (kN) } & \multicolumn{2}{|c|}{ 300NS (kN) } \\
\hline & & $\overline{\mathrm{x}}^{*}$ & $\mathrm{~S}_{\mathrm{x}}{ }^{* *}$ & $\overline{\mathrm{x}}$ & $\mathrm{s}_{\mathrm{x}}$ \\
\hline (1) & Local buckling of skin & 18.5 & 2.1 & 16.5 & 2.1 \\
\hline (2) & Web flexural failure & 38.6 & 5.9 & 33.1 & 3.8 \\
\hline (3) & Slippage of bottom flange to web & 38.3 & 6.3 & 31.4 & 3.0 \\
\hline
\end{tabular}



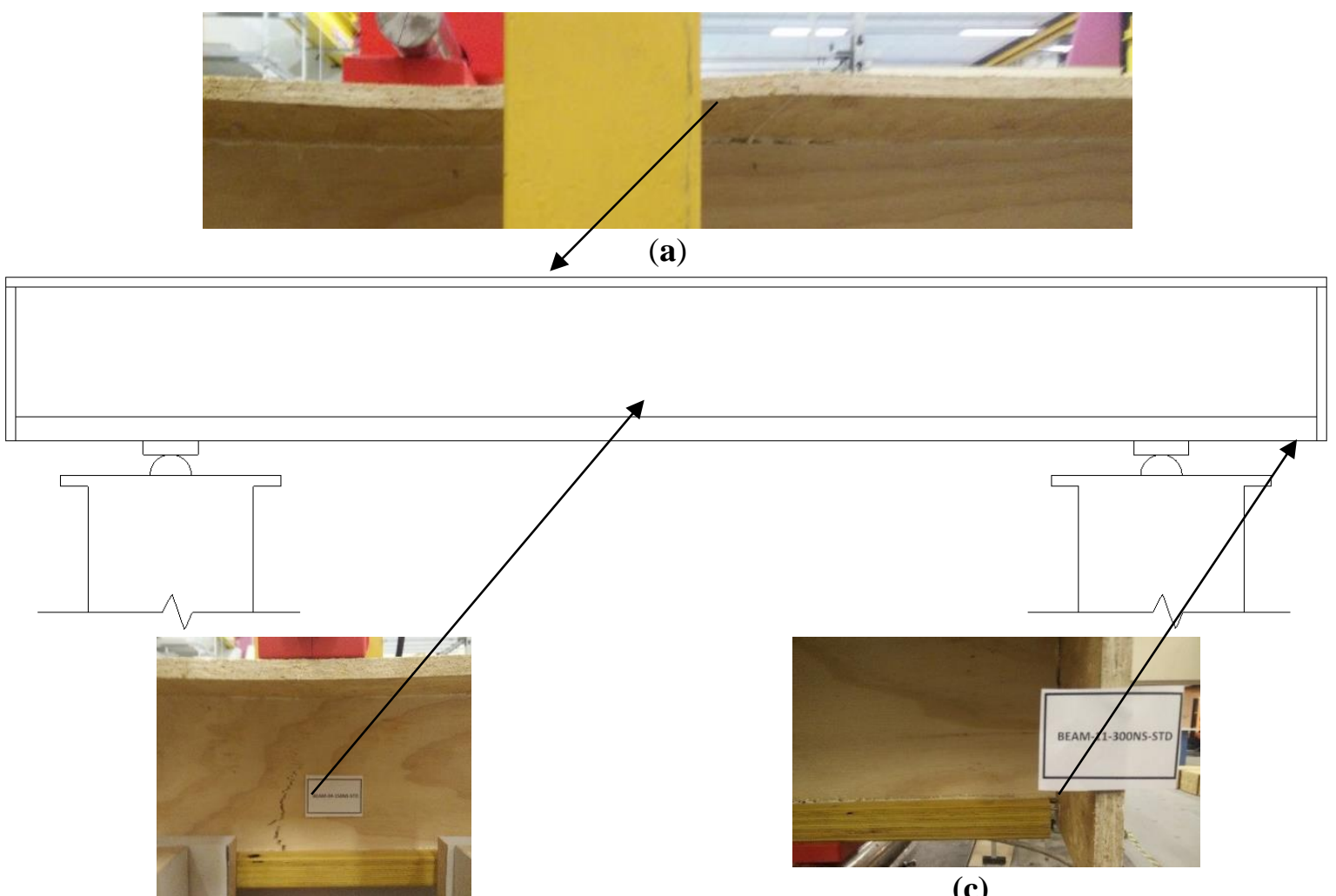

(b)

(c)

Figure 5. Failure modes observed for standard configurations: (a) Local Buckling of the top skin; (b) Flexural crack in web at centre span; (c) Slip failure of bottom flange to web (illustrated is the right side but may occur similarly on the left but not both).

\subsubsection{Local buckling of skin}

The first failure mode was the local buckling of the floor panel/stressed-skin whose onset was observed (Figure 5a) in the early stages of loading between the $15 \mathrm{kN}$ to $20 \mathrm{kN}$ mark. This behaviour proved the hypothesis which theorised as such due to the removal of the top flange from a traditional timber flooring cassette system. This causes the external load to be now also be taken up by the flooring panel, which has not been formally designed for this role. Apart from one exception as later indicated in Figure 7a, the occurrence local buckling of the skin for spacing specimens with $150 \mathrm{~mm}$ nail spacing occurred at a later stage of loading than that of the $300 \mathrm{~mm}$ nail spaced specimens. The extent of this postponement to the onset of buckling is on average approximately only $2 \mathrm{kN}$. However, it is important to note that with the specimens with the greater nail spacings, the extent of out-of-plane local buckling was greater which leads to separation in the floor-web connection. Thus, one of the influencing factors to the greater overall strength was the closer nailed specimens since they better maintained the floor-web connection. Importantly this may not necessarily be due to the support provided by the extra nails itself, but rather due to the better glued connection. This was facilitated by the closer nail spacings since they better press and hold the polyurethane glue during it curing process.

\subsubsection{Flexural failure of web}

The next failure mode was the cracking of the plywood web (Figure 5b), this also was gradual in onset and development. The onset of major web cracking was on average $5.5 \mathrm{kN}$ higher for the $150 \mathrm{~mm}$ nail spacing than for the $300 \mathrm{~mm}$. Generally, the beginning of the cracking occurred well after local buckling of the top floor 
panel and still comfortably before ultimate capacity. As web cracking propagated the forces were being continually transferred to the stronger bottom LVL flange whose connection to the web generally failed as a result of this. The location and orientation of the cracking was repeatedly shown not to be angled nor between reaction and applied force as a shear failure would suggest. A rolling shear failure across the plywood was not observed rather the cracks were vertical at centre span directly under the applied load. They originated from the bottom of the web where it experienced the greatest curvature and tension then slowly propagated vertically upwards indicative of a flexural failure of the web.

\subsubsection{Slip failure}

The final failure mode was that of the ultimate slip (Figure 5c) and detachment of the bottom flange to the web due to excessive web cracking causing high deflection and hence curvature along with forces too great to be carried by the connection to the bottom flange alone. The bottom flange made of LVL is nailed and glued to the web and takes the tensile load of the system. Regardless of the nail spacing this member was observed to remain intact up to and after a sudden spontaneous failure which has been attributed to the failure of the adhesive layer. This is also demonstrated in the slip results presented in Figure 6. Based on the total area of contact between the LVL and the web, it can be concluded that the polyurethane is providing notably more strength and stiffness than the nails which explains the similar observations across the tests prior to peak load. A typical slip response (BEAM - 06 - 150NS - STD) is shown below in Figure 6 which shows the data gathered supporting the observation that one half would suddenly slip and not the other. This is due to connection and material imperfections in both sides.

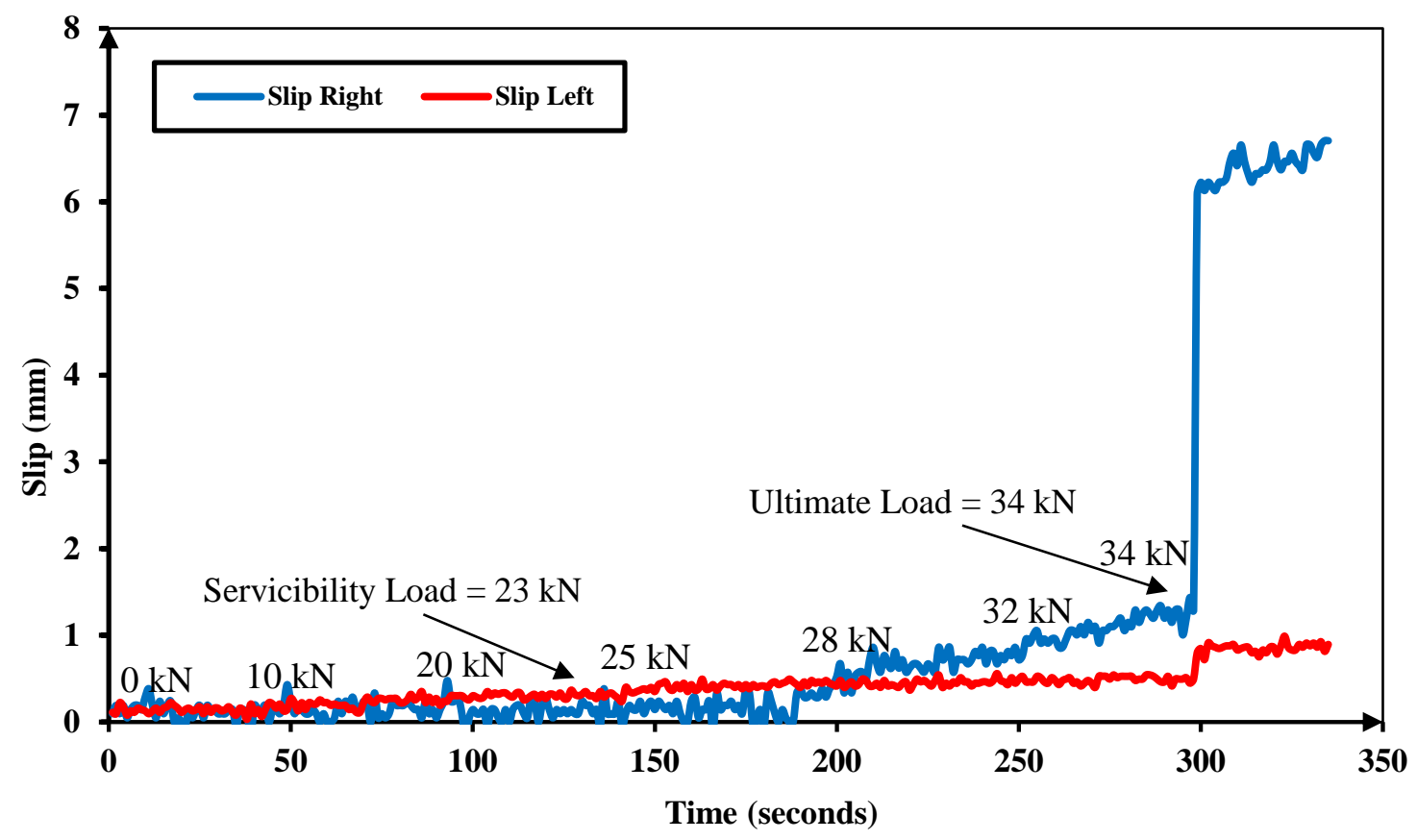

Figure 6. Measured slip of the left and right-hand sides with loading rate of $2 \mathrm{~mm} / \mathrm{min}$.

This failure mode always occurred either at the same time or shortly after flexural failure of the web. The damage due to flexural failure resulted in an average force for the slip failure to be lower. The connection in 
question failed in a shear action since the glue would reach its shear capacity and fail abruptly causing the nails to then deflect towards the ends of the joist. Further to this, halving the nailed spacings from $300 \mathrm{~mm}$ to $150 \mathrm{~mm}$ resulted in an increased shear resistance at this joint against slip failure, thus resulting in an average increase of capacity by $6.9 \mathrm{kN}$. Since this final failure mode is the ultimate failure of the floor system that occurs at or just after peak loading and is rapid in nature, the progression without instrumentation is unobservable. However, its likelihood can be predicted safely before its occurrence due to at least some progressive cracking of the web always occurring beforehand.

\subsection{Serviceability and Ultimate Load}

The serviceability limit state (SLS) as outlined in Australian Standards 1720.3 Timber structures design criteria is dependent on the load category [44]. Serviceability requirements exist so as to limit excessive deflection which is noticeable to the human eye and protect against potential cracking of rigid plaster architraves and panelling [45]. Two load combinations have been considered for SLS as in Table 5 as per serviceability calculations in AS1720.3 Table 4.1.3.3 and Table 4.1.3.5(B) [44]. In this case, the minimum of the two scenarios was taken as the deflection limit, this being $5 \mathrm{~mm}$. Whereas the Ultimate limit state (ULS) capacity was taken as the peak of each load-displacement graph.

Table 5. Serviceability limit loading and associated deflection limits.

\begin{tabular}{c|c|c|}
\hline Load category & Loading condition* & Deflection limits** \\
\hline 1 & $\mathrm{G}_{1}+\mathrm{Q}_{1}$ & $\operatorname{Min}(\mathrm{L} / 300$ or $15 \mathrm{~mm})=6 \mathrm{~mm}$ \\
\hline 2 & $\mathrm{Q}_{2}$ & $\operatorname{Min}(\mathrm{L} / 360$ or $9 \mathrm{~mm}=5 \mathrm{~mm}$ \\
\hline
\end{tabular}

*Where: $\mathrm{G}_{1}-$ Distributed load, $\mathrm{Q}_{1}, \mathrm{Q}_{2}-$ Imposed action; ** $\mathrm{L}-$ Span length.

The average serviceability load for the $150 \mathrm{~mm}$ nail spacing specimens was $24.2 \mathrm{kN}$ with a standard deviation of $1.5 \mathrm{kN}$. This is similar to the average serviceability load for the $300 \mathrm{~mm}$ nail spacing specimens which was $22.6 \mathrm{kN}$ at a standard deviation of $1.9 \mathrm{kN}$. This is highlighted in Figure 7 through the dashed line. These results suggests that the initial stiffness is not dissimilar between the varying nail spacings. This is proven to be the case as the average stiffness is $4.6 \mathrm{kN} / \mathrm{mm}$ for the $150 \mathrm{~mm}$ nail spacing configuration and $4.4 \mathrm{kN} / \mathrm{mm}$ for the $300 \mathrm{~mm}$ nail spacing. This is thought to be due to the polyurethane adhesive being used on the entire area between each of the joins to form a firm connection taking much of the load at the connection in the initial and early stages of loading. Whereas the nails are having less of an overall impact and are primarily complementary to add further shear strength and ductility to each join particularly in later stages of loading.

The ultimate capacity shows a greater difference in results than that of serviceability in that the specimens. The $150 \mathrm{~mm}$ nail spacings specimens on average perform to a higher level than that of the $300 \mathrm{~mm}$ nail specimens as shown in Figure 7. The average ultimate limit for the $150 \mathrm{~mm}$ nail spacing specimens was $38.8 \mathrm{kN}$ with a standard deviation of $5.6 \mathrm{kN}$. The average ultimate limit for the $300 \mathrm{~mm}$ nail spacing specimens was $33.1 \mathrm{kN}$ with a standard deviation of $3.7 \mathrm{kN}$. This is due to the different strength of the connection in how well the skin is affixed to the web and the slip of the bottom flange to the web which can be seen by the performance and failure modes (1), (2) and (3). 


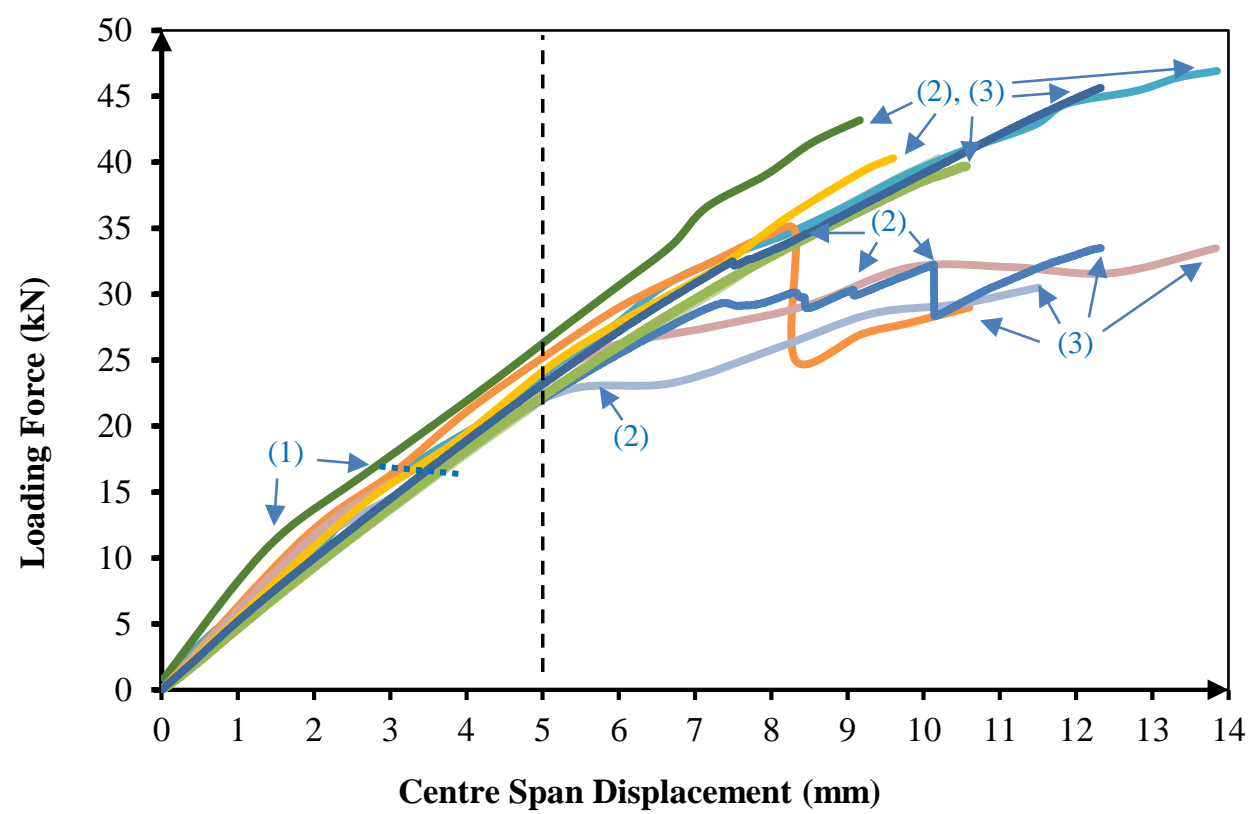

(a)

(1) Local buckling of the web;

(2) Flexural web failure;

(3) Slip between the bottom flange and the web.

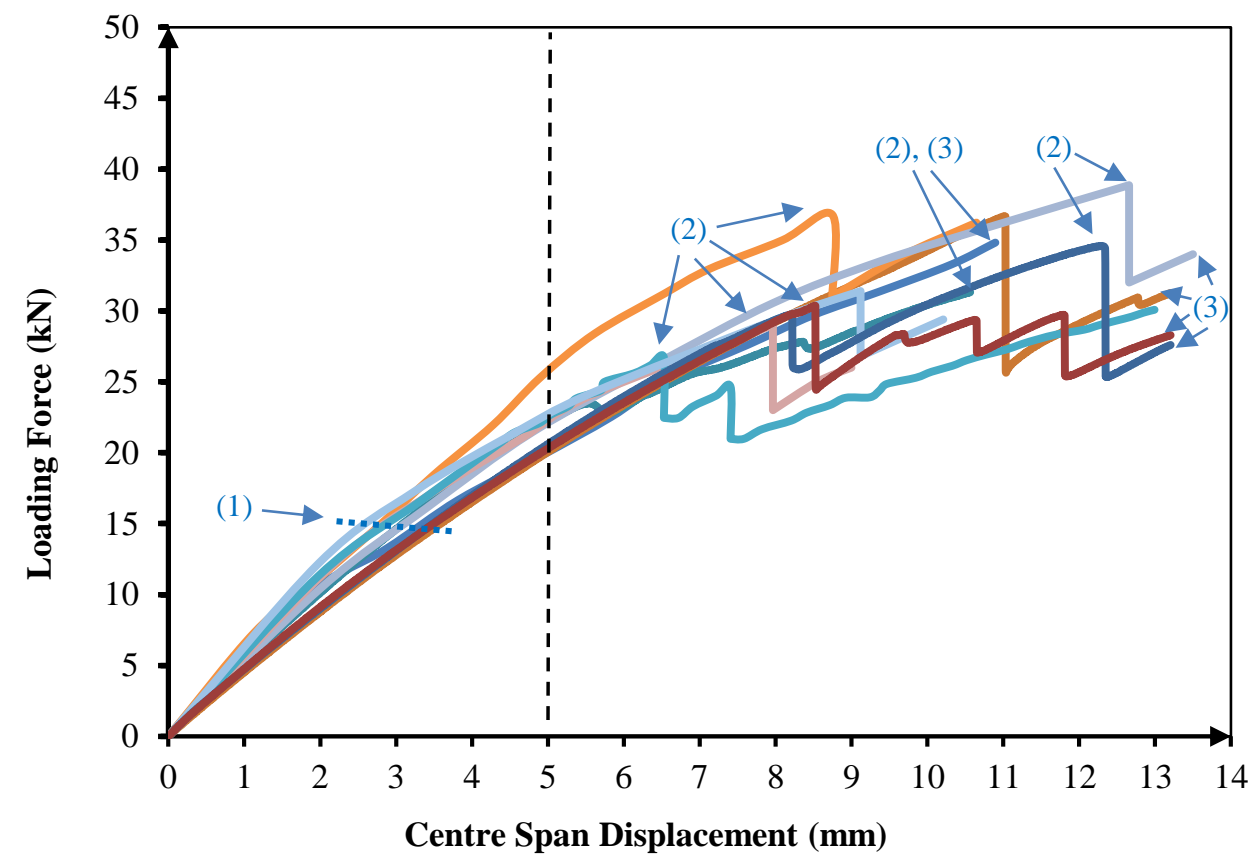

(b)

Figure 7. Experimental results up to ultimate failure: (a) $150 \mathrm{~mm}$ Nail Spacing; (b) $300 \mathrm{~mm}$ Nail spacing.

The absolute peak capacity occurring in any one of the $150 \mathrm{~mm}$ nail spacing configurations was $47.0 \mathrm{kN}$. This absolute peak value was tested in that it was almost reached a few more times during testing which verifies that 
this result wasn't an anomaly. The maximum peak capacity for any one of the $300 \mathrm{~mm}$ nail spacing configurations was $36.8 \mathrm{kN}$, again this value was tested in that it was almost reached a few more times during testing verifying that this is indeed the absolute maximum capacity from this configuration. This shows a significant potential improvement of $27.7 \%$ in the ultimate load capability stressed-skin engineered timber floor cassettes by simply halving the nail spacing based on peak value results and $17.2 \%$ increase based on average results. The justification in why such a stark improvement in the load carrying capability on the floor systems with the same geometry and materials is two-fold. Firstly, due preventing and delaying the failure modes of local buckling of the stressed-skin due to separation of the OSB panel to the top of the web, and secondly, due to the delay of the slip/join failure of the bottom LVL flange and the web. Therefore, having an appropriate nail spacing is important to delay the failure modes of the stressed-skin floor system and increase its capacity.

\section{$4 \quad$ Finite Element Analysis}

Appropriate methods in ABAQUS has been used as an established and proven means to simulate the performance and behaviour of sawn-cut and engineered timber under numerous conditions [46, 47]. This includes delamination [48], buckling of oriented strand board webbed wood I-joists [49], nailed layered beams [50], timber with cracks [51] and flaws [32], nailed joint [52], timber with steel dowel connections [34], moisture variations [1] and timber pegged connections [33].

\subsection{FEA Modelling Technique}

Abaqus CAE 2017 [53] was used with explicit analysis to model the entire experimental specimen in detail. This included using the appropriate materials (OSB, PLY, LVL), connections (polyurethane adhesive and embedded nails) and support conditions (pin-roller for reactionary along with lateral restraint parallel to the direction of loading). Each of the EWPs were modelled with an appropriate orthotropic material model with previously outlined material constants in Tables 1, 2 and 3. Each of the engineered timber materials were used with their primary strength and spanning direction in mind. This was accounted for with the orthotropic characteristics aligned through the use of appropriate local orientations.

Glue was modelled with the tested and measured parameters as a cohesive interaction due to the thinness and stiffness of the glueline. This decision to model the glue using cohesive interaction over cohesive elements is to significantly reduce the computational cost [47]. Since squeeze out of the glue was always observed, the assumption was made that full coverage of the adhesive was at the bond lines with the found properties. Moreover, another interaction property was established to capture the general friction coefficient of wood to steel of 0.2 for kinetic $\left(\mu_{\mathrm{k}}\right)$ and 0.38 for static friction $\left(\mu_{\mathrm{s}}\right)$ [54].

A 3D deformable element with 8-node linear brick and reduced integration (C3D8R) was used to model the web, skin, bottom flange and rimboard. A two node linear beam element (B31) was used to appropriately model the nails which were embedded into the plywood web through each adjoining element since they were expected to primarily experience shear forces [46]. The nails were modelled with a mild steel material of modulus of elasticity of $200 \mathrm{GPa}$ and with AS1720 [30] being used for the highest stress values as that of the strength of the joint. 
Detailed crack modelling was undertaken due to the results of the experimental program indicating a significant crack in the web at centre span developing prior to achieving ultimate load and propagating as the load continued to increase. Since the location of the crack was known and was repeated consistently throughout the experimental program, a vertical split in the web was made for detailed crack analysis. An additional 3D deformable part was made to model the crack propagation at this location in centre span, this was a cohesive element type of $2 \mathrm{~mm}$ thickness utilising the traction-separation law method. This modelled the timber material properties for this type of cracking behaviour with the appropriate max stress failure criteria and element removal. Linear softening and mode independent damage evolution with fracture energy of 0.7 was used in accordance to established techniques as outlined in detail for similar applications in timber beams in bending in literature $[5,55,56]$ and successfully used in LVL beams and members $[57,58]$ but specifically in plywood [59] which is also the material used for the webs in the stressed-skin flooring system. It has been established as an appropriate and innovative means to model cracks in timber with the major caveat the location must be known beforehand. This was exactly what was repeatedly observed in the experimental program [57, 60-62].

\subsection{FEA results}

Although the finite element analysis in totality is computationally demanding due to the use of cohesive elements, it did however successfully replicate the observed failure modes and behavioural response of the tested specimens. This in turn led to the force-displacement behaviour to be well simulated and allowed for preliminary adjustment of parameters to determine their general effect on the captured failure modes. Figure 8a displays the stress distribution of the beam when loaded within its elastic region. As expected, regions at the centre and near the location of load application show a greater stress level and concentration. The local buckling of the skin occurs next as shown in Figure $\mathbf{8 b}$ where a wave like displacement profile can be seen and loading continues to increase rather steadily just as per experimental observations.
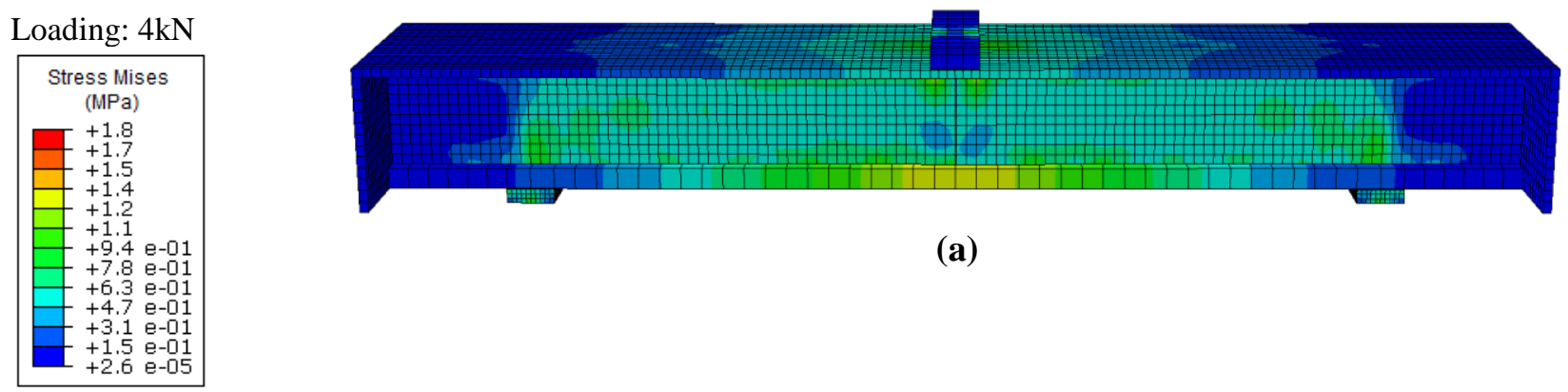

(a)

Loading: $16 \mathrm{kN}$
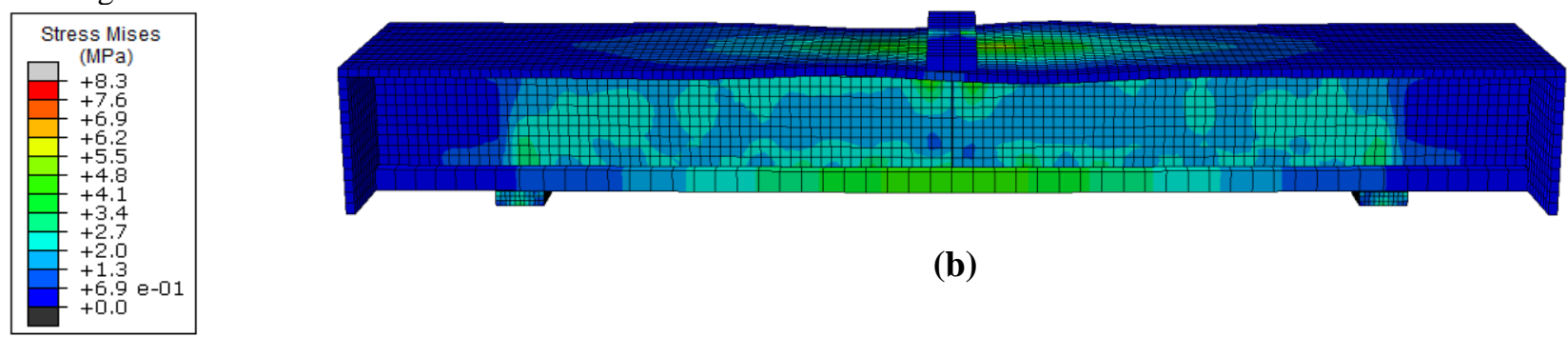

(b)

Figure 8. Finite element analysis (FEA) stress distribution during: (a) Loading within the elastic limit; (b) Local Buckling of top skin occurring 
The progression of the local buckling of the skin can be seen even without observing the displacement profile through the stress distributions from the top and bottom. Figure 9a depicts a stress distribution in which the variation is generally uniform vertically, whereas in Figure 9b, the variation of stress has evolved to be elliptical in nature. The key point being, that the stress is unloaded along the long edges, which indicates clearly that the skin has undergone local buckling. This analysis shows an alternative check for local buckling which doesn't rely on the visual perception of displacement nor any arbitrary local maximum deflection limit to classify a stressed-skin member as locally buckled.

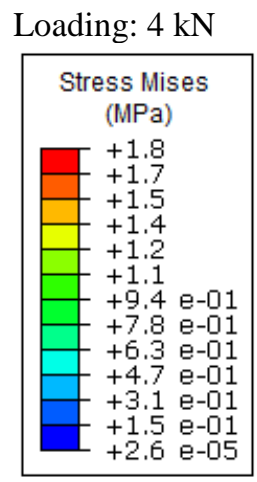

Loading: $16 \mathrm{kN}$

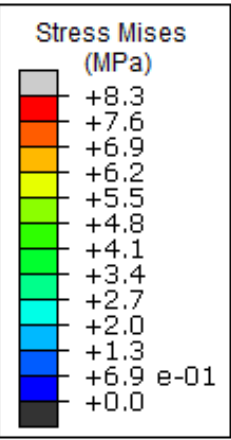
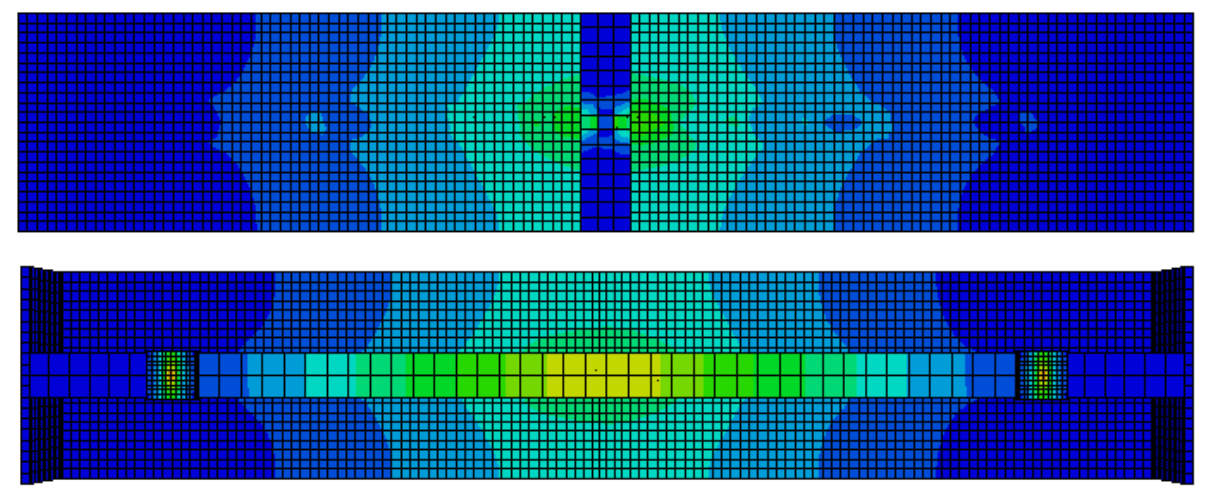

(a)
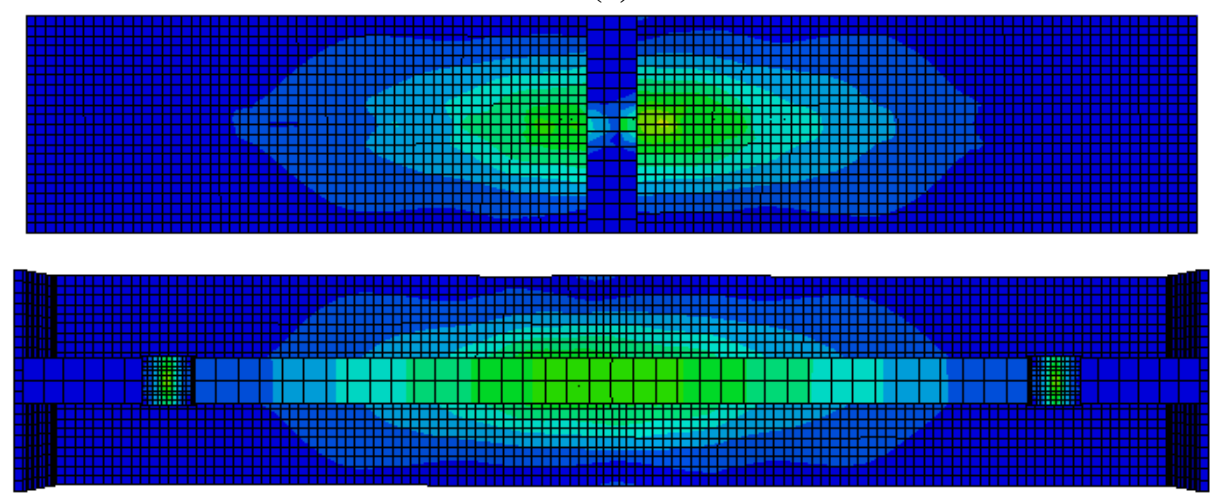

(b)

Figure 9. Top and bottom view of the stress distribution and pattern: (a) Prior to local buckling of top skin; (b) Post local buckling of top skin

The cohesive elements which were placed vertically through the web at mid-span generally maintain their dimension through the elastic loading stage as shown in Figure 10a. When loading and displacement is increased to the extent that the top skin undergoes local buckling, the elements begin to stretch and compress as can be seen in Figure 10b by the difference in element width. Loading continues and eventually an element will exhibit a stress greater than that of the strength criterion to which it is assigned and gets eliminated, stresses are then recalculated on the remaining elements and the loading continues. In this way the cohesive elements were used to approximately model the initialisation and growth of cracks. 


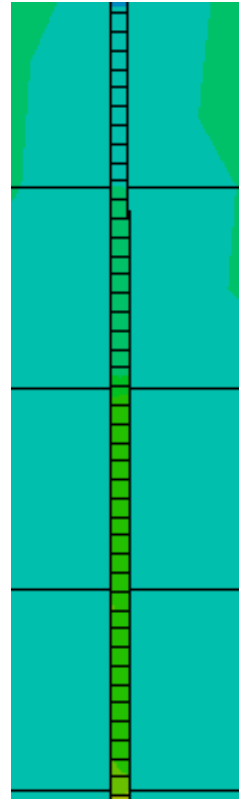

Loading: $4 \mathrm{kN}$

(a)

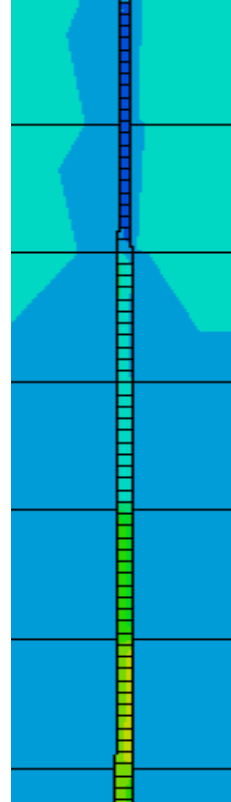

Loading: $16 \mathrm{kN}$

(b)

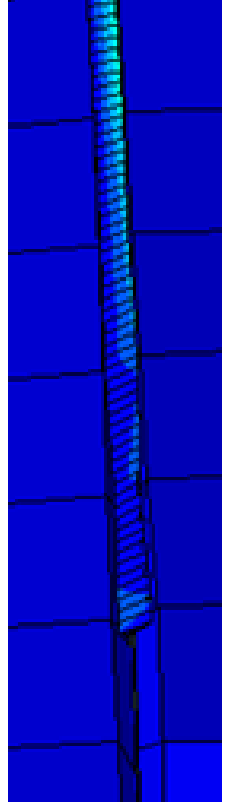

Loading: $30 \mathrm{kN}$

(c)

Figure 10. Cohesive element crack development: (a) Elastic loading; (b) During local buckling of top flange; (c) Web crack failure

The finite element analysis shows a strong similarity in initial secant stiffness for both the nail spacings, which were along the upper bounds of experimentally tested results. The simulated stiffness of approximately $5.4 \mathrm{kN} / \mathrm{mm}$ is generally maintained up for the most part of the serviceability limit as shown by the vertical dashed line in Figure 11. At higher displacements the magnitude of the load difference is more pronounced up until ultimate load and critical failure as shown in the graph up of the FEM results in Figure 11.

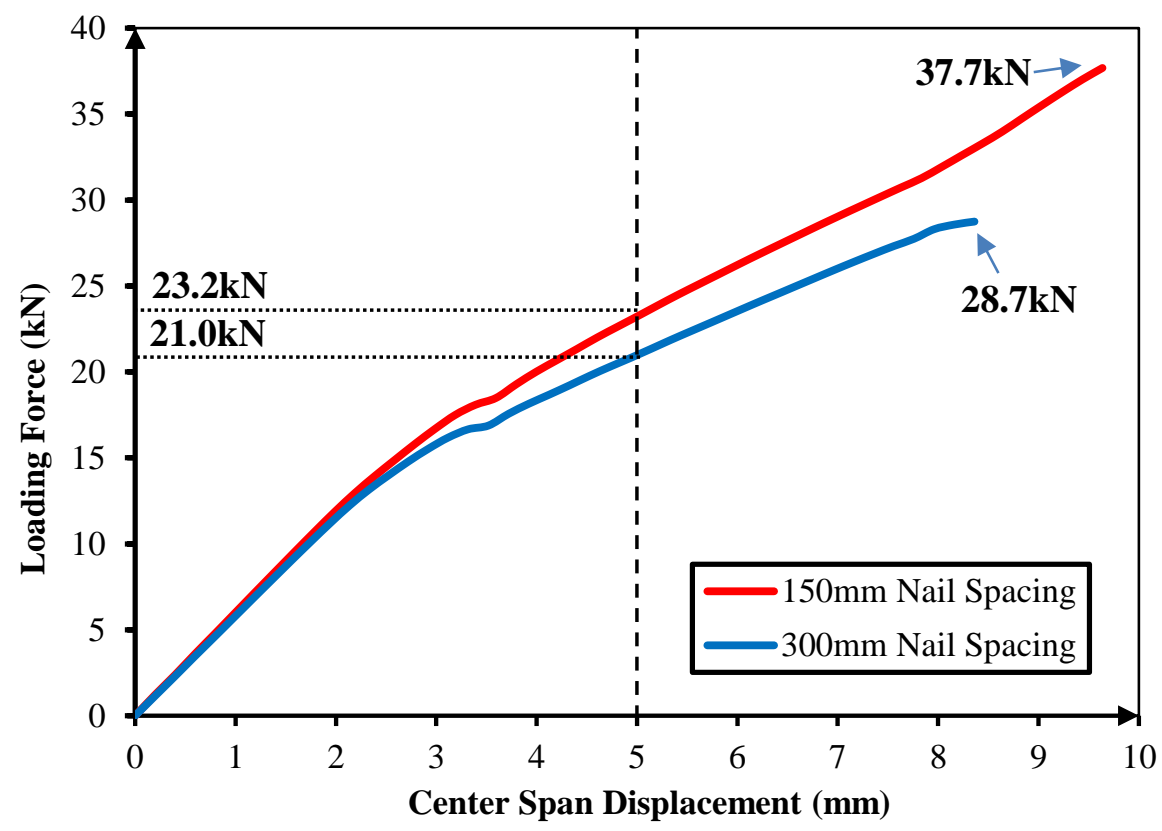

Figure 11. Force - deflection graph of FEM results for $150 \mathrm{~mm}$ and $300 \mathrm{~mm}$ nail spacing specimens. 


\subsection{Validation of FEA}

A comparison between the FEA and experimental results is shown in Figure 12a and 12b. They demonstrate a good agreement and provide confirmation that this method can approximately simulate the actual behaviour accurately, however at the cost of computational time. The experimental tests at $150 \mathrm{~mm}$ nail spacing produced an average maximum capacity and serviceability load of $38.8 \mathrm{kN}$ and $24.2 \mathrm{kN}$ as compared to the $37.7 \mathrm{kN}$ and $23.2 \mathrm{kN}$ predicted with the FEM. That is, the FEM is only $2.8 \%$ conservative for Ultimate Limit State (ULS) and $4.1 \%$ conservative for SLS which shows great agreement. The experimental tests at $300 \mathrm{~mm}$ nail spacing produced an average maximum capacity and serviceability load of $33.1 \mathrm{kN}$ and $22.6 \mathrm{kN}$ as compared to $28.4 \mathrm{kN}$ and $21.0 \mathrm{kN}$ with the FEM. That is, the FEM is $14.2 \%$ conservative for ULS and $7.1 \%$ conservative for SLS which shows a good agreement but with greater conservativity. Moreover, the predicted mid-span lateral deflection at these maximum values are also comparable for the standard $150 \mathrm{~mm}$ and $300 \mathrm{~mm}$ spacing specimens. The primary reasons of some discrepancy for specifically the peak load results may be due to the number of complex failure mechanisms of the glue and nail connection to timber, and how well that was captured in small scale test to derive the parameters for the traction-separation method used. In addition, natural irregularities and variations in the timber at a larger scale than that of the smaller sections used to gather the material properties and the consistency of the factory-based manufacturing methods used to create the specimens may have also influenced some discrepancy.

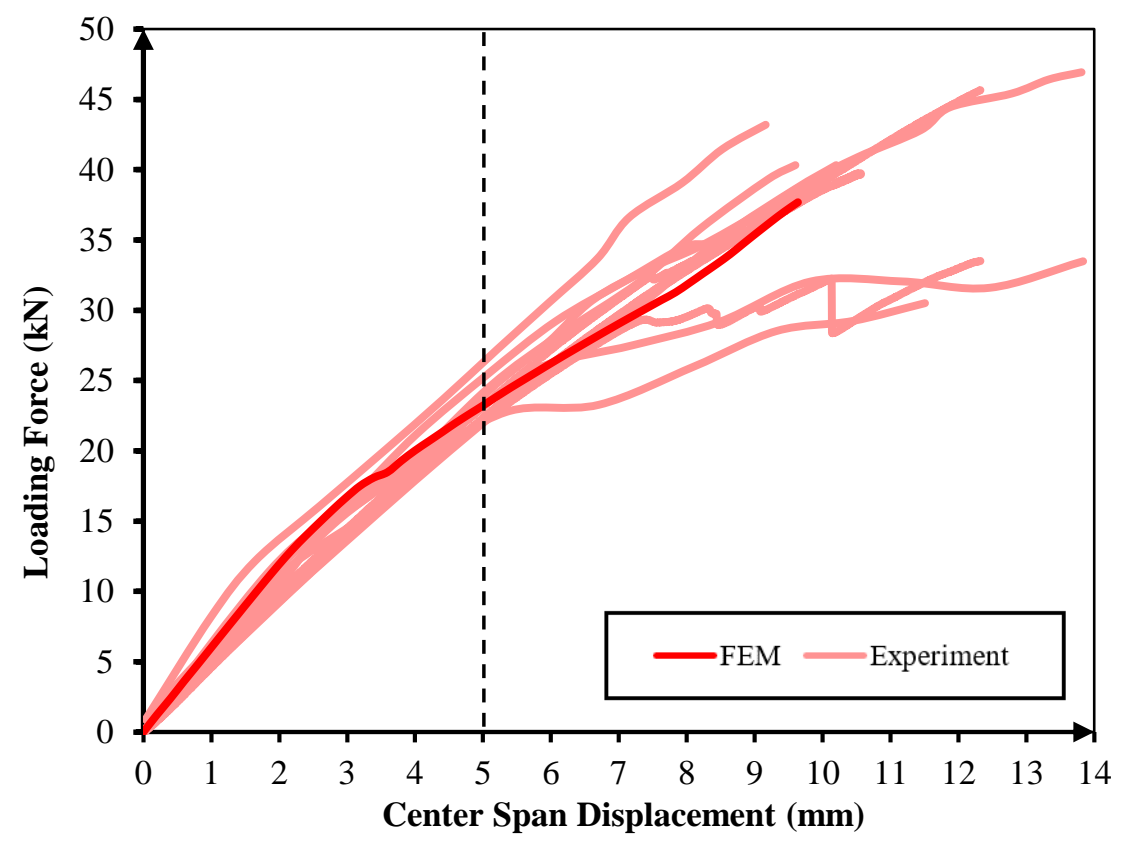

(a) 


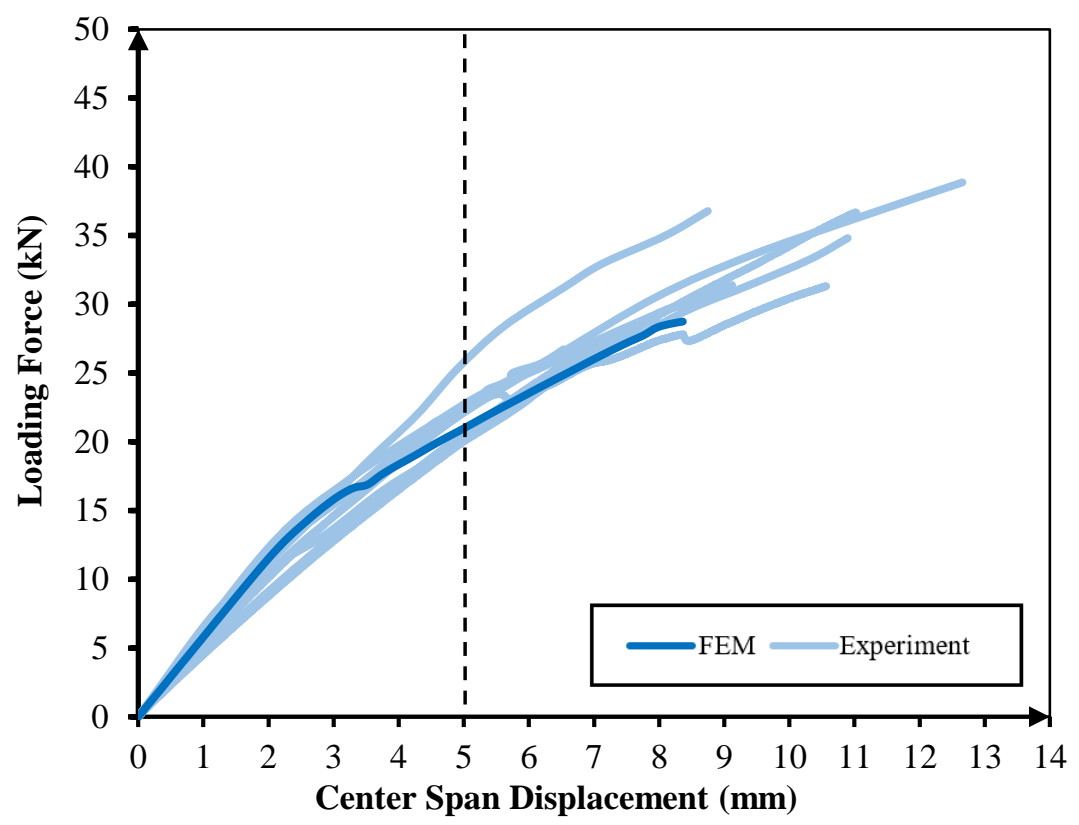

(b)

Figure 12. Load-deflection comparison between FEM model and Experimental samples up to ultimate load: (a) $150 \mathrm{~mm}$ nail spacing; (b) $300 \mathrm{~mm}$ nail spacing.

\section{Parametric study}

Local buckling has been observed in the flooring panel due to the removal of the top flange and integrated use of this member as a stressed-skin prior to other failure mechanisms initiating. An introductory parametric study has been carried out to understand this issue and potentially remediate it through design parameter changes. This is justified at least on a preliminary level, since the FEA has successfully simulated the failure modes and the force and displacement in accordance to the experimental testing done. Parameters which were investigated included the adhesive properties, the ratio of clear effective outstand width of the flange to the thickness of the stressed-skin $\left(b_{\text {eff, }, d} / t\right)$, ratio of the clear depth of the web to the thickness of the web $\left(d_{p} / t_{w}\right)$, ratio of the clear span to the total depth of the composite beam $\left(L_{d} / D\right)$ and finally the spacing of the nails. Parameters which were not changed included the joist spacing. This was because in the Australian building industry, the standard spacing of joists is $450 \mathrm{~mm}$ so that they align with the spacing of the timbers studs in the walls which support them [31]. Additionally, the total depth has been kept at a constant level of $300 \mathrm{~mm}$. This is such that it does not impede on typical floor to ceiling heights of adjacent rooms own spanning floor cassettes. Yet this depth still allows for services to run alongside the joists which is expected since this flooring system is designed for shorter spans such as in corridors. As a default the nail spacings were $150 \mathrm{~mm}$ to balance time and cost in manufacturing with performance. Lastly the bottom flange which is a commonly available 90x45 mm LVL section has been kept constant as it is not the primary cause for any of the failure modes.

\subsection{Skin Slenderness}

Considering the local buckling of the skin due to the removal of the top flange and slenderness effects as seen in the experimental program, the skin slenderness ratio is investigated. In this case the thickness to effective 
width ratio of the OSB flooring panel used as the stressed-skin. The aim in increasing the skin thickness $(t)$ and hence decreasing the slenderness ratio is to reduce the local buckling and hence provide a greater use of the stressed-skin as an integral part of the structural system without resorting to less cost-efficient EWPs such as plywood. The slenderness ratio for the skin uses an effective width in accordance to design guidelines as shown in Equation 1 [63].

$$
b_{f, c}=\left(b_{w}+0.1 * \text { span }\right) \leq \text { spacing }
$$

Where,

$$
\begin{aligned}
& b_{f, c}=\text { width of the compression member (top) } \\
& \qquad b_{w}=\text { width of the web }
\end{aligned}
$$

Hence for a web width of $21 \mathrm{~mm}$ and a span of $1800 \mathrm{~mm}$,

$$
b_{f, c} \leq 201 \mathrm{~mm}
$$

Therefore, for an effective width of the skin of $198 \mathrm{~mm}$ the outstand width is $100.5 \mathrm{~mm}$ with its clear outstand width $\left(b_{e f f, o}\right)$ of $90 \mathrm{~mm}$.

Thicker flooring skins than the minimum $18 \mathrm{~mm}$ OSB panel to span the $450 \mathrm{~mm}$ joist spacing has been selected to tackle the local buckling of the stressed-skin. Although a tailored specific thickness of OSB can be produced through consultation timber manufacturers, minimum supply order and increased cost has led to the use of common available thicknesses to be incorporated and studied. The common thicknesses of OSB which are greater than $18 \mathrm{~mm}$ and are mass produced and available in the Australian market are $20 \mathrm{~mm}, 22 \mathrm{~mm}$ and $25 \mathrm{~mm}$ [64], thus these are the thicknesses used in the floor system which were investigated for performance. Each skin thickness was used in combination with the standard configuration presented prior with a nail spacing of $150 \mathrm{~mm}$ due to the balance between cost of manufacture and the corresponding increase in performance. The behaviour is depicted in Figure 13 with failure modes (1), (2) and (3) as per Table 4 superimposed, with key results summarised in Table 6.

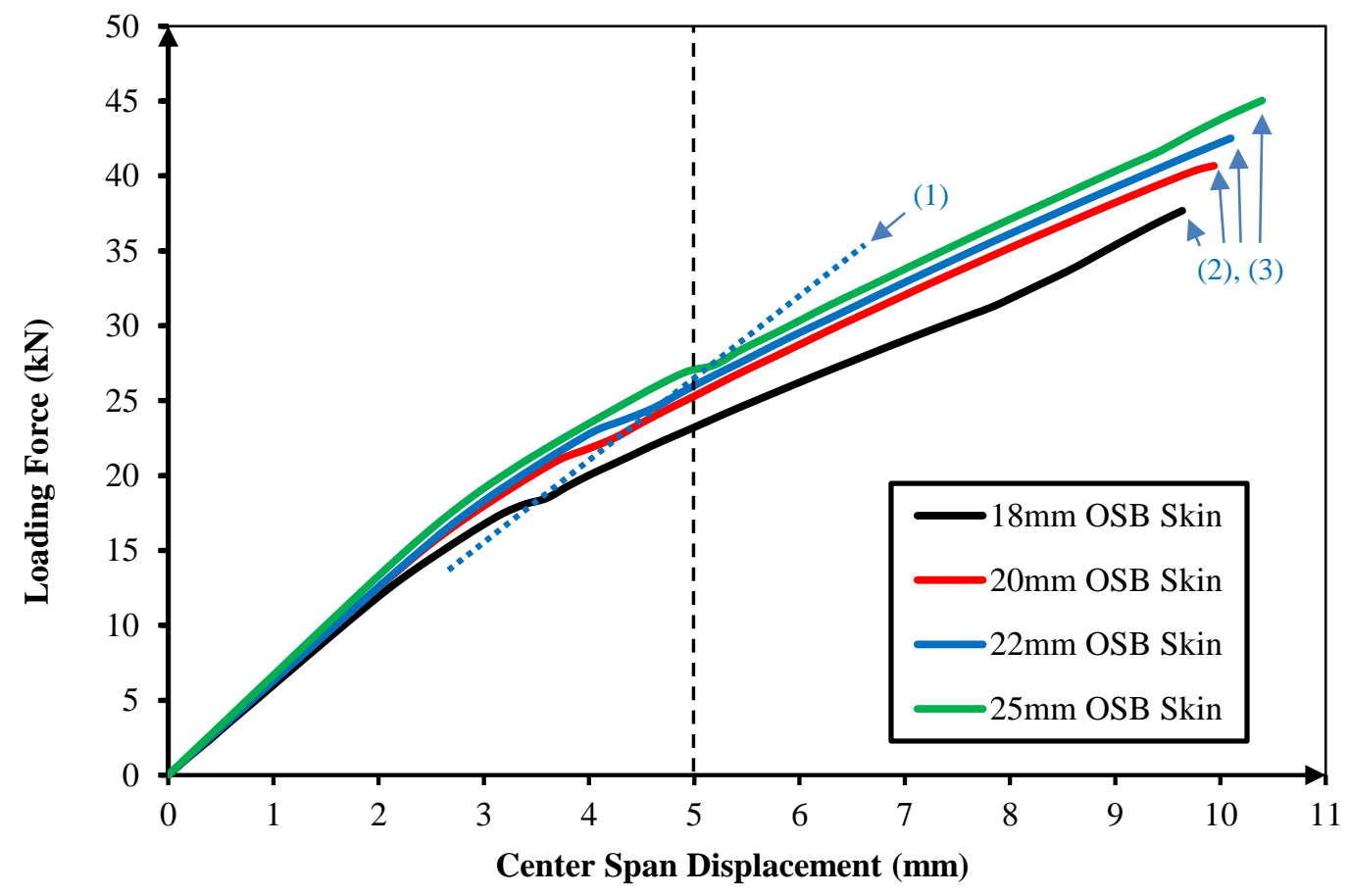


Figure 13. Force - deflection behaviour when increasing skin thickness.

Table 6. Result summary of decreased slenderness ratio of the skin on performance

\begin{tabular}{|c|c|c|c|c|}
\hline $\begin{array}{c}\text { Skin } \\
\text { thickness } \\
(\mathbf{m m})\end{array}$ & $\begin{array}{c}\text { Skin slenderness ratio } \\
\left(\boldsymbol{b}_{\text {eff, } \boldsymbol{o}} / \boldsymbol{t}\right)\end{array}$ & $\begin{array}{c}\text { Serviceability } \\
\mathbf{l o a d}(\mathbf{k N})\end{array}$ & $\begin{array}{c}\text { Ultimate load } \\
\text { capacity }(\mathbf{k N})\end{array}$ & $\begin{array}{c}\text { Displacement } \\
\text { at maximum } \\
\text { load (mm) }\end{array}$ \\
\hline 18 & 5.0 & 23.3 & 37.7 & 9.6 \\
20 & 4.5 & 25.6 & 40.7 & 9.9 \\
22 & 4.1 & 26.0 & 44.3 & 10.1 \\
25 & 3.6 & 27.0 & 45.0 & 10.4 \\
\hline
\end{tabular}

The positively sloped dotted line in Figure 13 indicates improvement in both the onset and severity of local buckling of the top skin which now occurs at higher loads and displacements when the skin thickness is increased. Once the skin thickness is increased to $25 \mathrm{~mm}$, that is, the top skin having a slenderness ratio of 3.6 the point of local buckling passes the serviceability limit. Greater increase in performance in the ultimate load capacity then the serviceability load is observed due to the minimisation of the local buckling of the skin which is most prominent after the $5 \mathrm{~mm}$ deflection, this governs the serviceability requirements. With the increase of thickness of the OSB skin the displacement at maximum load is impacted by the overall stiffness of the floor system being increased but countered by the greater load carrying capability due to the delaying of local buckling of the stressed-skin. Decreasing the slenderness ratio of the skin to 4.5 at this span results in much of the gain in performance to be realised. For the standard $450 \mathrm{~mm}$ joist spacings this corresponds to a minimal thickness of $20 \mathrm{~mm}$, which is $2 \mathrm{~mm}$ more than the minimum thickness of floor panel in regular timber flooring cassettes.

\subsection{Web Slenderness}

Since the plywood web cracking was found to be a critical failure mode, the parameter of web slenderness was investigated with the aim to achieve higher ultimate loads through the delay of this failure mode. The slenderness ratio of the web was calculated through the ratio of $d_{p} / t_{w}$ where $d_{p}$ is the depth of the web from the top of the bottom flange to the underside of the skin and $t_{w}$ is the thickness of the web [65]. Although a tailored specific thickness of plywood can be produced, local commonly available thicknesses have been chosen for practicality and feasibility purposes. The commonly available thicknesses of plywood's which are greater than $21 \mathrm{~mm}$ and are produced and available in the Australian market are $25 \mathrm{~mm}, 32 \mathrm{~mm}[29,66]$ thus these are the thicknesses used in the FEM analysis to investigate behaviour and the increase in performance as depicted in Figure 14 with key data summarised in Table 7. 


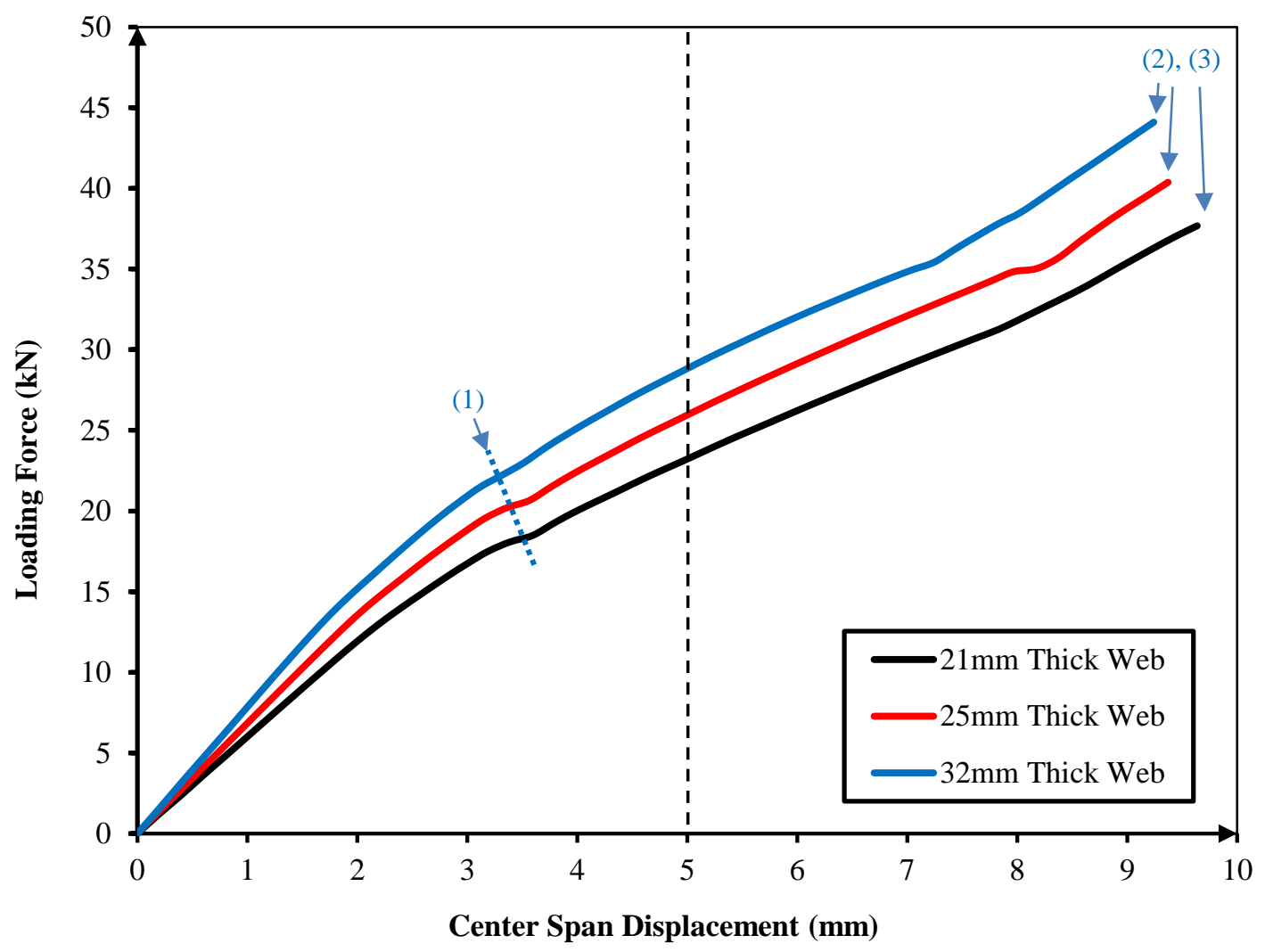

Figure 14. Force - deflection behaviour when increasing web thickness.

Table 7. Result summary of decreased slenderness ratio of the web on performance.

\begin{tabular}{|c|c|c|c|}
\hline $\begin{array}{c}\text { Web thickness } \\
(\mathbf{m m})\end{array}$ & $\begin{array}{c}\text { Web slenderness } \\
\text { ratio }\left(\boldsymbol{d}_{\boldsymbol{p}} / \boldsymbol{t}_{\boldsymbol{w}}\right)\end{array}$ & $\begin{array}{c}\text { Serviceability load } \\
(\mathbf{k N})\end{array}$ & $\begin{array}{c}\text { Ultimate load capacity } \\
(\mathbf{k N})\end{array}$ \\
\hline 21 & 11.3 & 23.3 & 37.7 \\
25 & 9.5 & 25.9 & 40.4 \\
32 & 7.4 & 29.1 & 44.1 \\
\hline
\end{tabular}

Decreasing the slenderness ratio of the web has a positive effect on the serviceability and ultimate load capacities, however, it is not as pronounced as that compared with those attributed with the decrease of nail spacing. The negatively slopped dotted line in Figure 14 indicates that increasing the web thickness decreases the displacement at which local buckling onset occurs, however, since the web is now thicker the load at which this occurs is higher. Decreasing the slenderness ratio by $16 \%$ from the $21 \mathrm{~mm}$ thickness configuration results in a $11 \%$ increase in serviceability load and $7 \%$ increase in ultimate load capacity. Additionally, a further reduction of the slenderness ratio by another $22 \%$ results in a $12 \%$ increase in serviceability load and a $9 \%$ increase in ultimate load capacity. Therefore, this shows that an increase in serviceably load and ultimate load can be achieved in a regular predictable manner through increasing the thickness of the web regardless of what thickness it is. To increase overall performance efficiently, the thickness of the plywood web may remain at $21 \mathrm{~mm}$ if the thickness of the OSB is increased by $3 \mathrm{~mm}$ from $18 \mathrm{~mm}$, as it has similar increase in performance per material increase but with less cost due to the nature of the material. If desired, the thickness of the web in this configuration can be increase to $25 \mathrm{~mm}$ with a slenderness ratio of 9.5 and above to meet higher capacities, 
as this produces a direct increase in overall performance in resisting bending. This is due to its orientation and moment of inertia. Furthermore, this is also due to the increase in the surface area of the bond line aiding in the prevention of slip.

\section{$5.3 \quad$ Nail Spacing}

The nails themselves have been kept constant with a diameter of $3.05 \mathrm{~mm}$ and length such that each nail is embedded a minimum of $30 \mathrm{~mm}$ into the web. This is governed by component availability, costing and considerations for management of efficient manufacturing and supply chains. Rather than the nails themselves, the spacings of the nails have been altered for investigation. That is, closer nail spacings take particular consideration of the connection between the skin to the web and the bottom flange to the web have been studied. Specimens with a $300 \mathrm{~mm}$ nail spacings along with a reduce $150 \mathrm{~mm}$ nail spacing has been modelled and validated showing a notable increase of $8.9 \mathrm{kN}$ in maximal capacity despite the onset of local buckling still occurring its magnitude is reduced as indicated by the vertical dotted line in Figure 15. The FEM model has supported experimental observations and allowed for modelling of a further reduced nail spacing of $75 \mathrm{~mm}$ for academic purposes. This does not take into consideration of the amount of extra time and cost in manufacturing these floor cassettes over those of $150 \mathrm{~mm}$ or $300 \mathrm{~mm}$ nail spacing, due to this process being if desired and invested upon, automated. The effects of halving the nail spacing once more to $75 \mathrm{~mm}$ shows a moderate increase in serviceability capacity of $4.2 \mathrm{kN}$ and $6.1 \mathrm{kN}$ as compared to the $150 \mathrm{~mm}$ and $300 \mathrm{~mm}$ scenarios. The failure modes (2) and (3), that is, the flexural failure of the web and the slip of the bottom flange of the web remain unchanged in terms of order. That is the web first progressively fails and in doing so transfers the load to the bottom flange and its connection to the damage web then fails. However, as observed only the most spaced out nail spacing showed minor web cracking.

The results of the further reduced nail spacings are more significant when a maximum capacity is of concern, particularly when compared to the $300 \mathrm{~mm}$ nail configuration. There is an increase of ultimate load of $7.2 \mathrm{kN}$ compared to the $150 \mathrm{kN}$ nail spacing, and $16.3 \mathrm{kN}$ compared to the $300 \mathrm{~mm}$ nail spacing of the same standard outlined configuration. The entire behaviour of which is depicted below in Figure 15. This indicates that reducing the nail spacing does indeed lead to a notable increase in ultimate performance. This is partly due to minimising the effect of local buckling of the stressed-skin and partly due to increasing the shear resistance of the joint to the bottom flange against ultimate slip failure. 


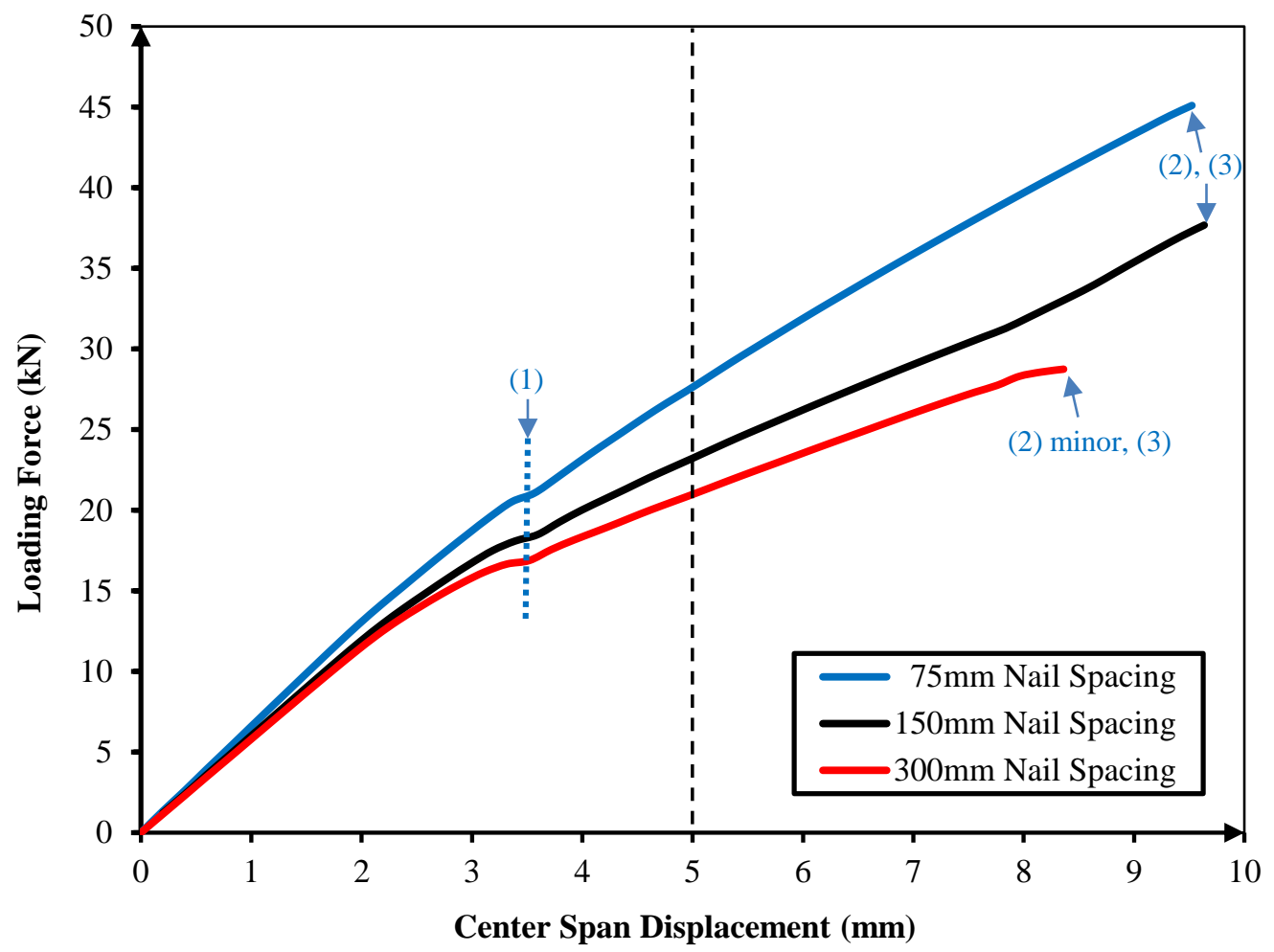

Figure 15. Ultimate force - deflection behaviour of FEM models of stressed-skin floor cassettes with nail spacings of $75 \mathrm{~mm}, 150 \mathrm{~mm}$ and $300 \mathrm{~mm}$.

\subsection{Adhesive Properties}

Adhesives incorporated into the stressed-skin flooring system play a highly critical role in the ultimate capacity and behaviour. Particularly, those between the web and skin as well as in between the web and the bottom flange. This is due to the integral engagement of the floor panel, that is, the stressed-skin to the web and the critical slip failure mode of the bottom flange. The motive for this part of the parametric study lies in the fact that the original glue and glue properties were for a simple flexible form of $1 \mathrm{C}$ polyurethane with the product name sika-221 with stronger and stiffer $2 \mathrm{C}$ (two component) polyurethane glues available. In addition, the manufacturing conditions which were used to create the specimens used to test the glue properties along with the test specimens were such that the glue cured under nail pressure only, leaving much room for improvement. Moreover, this not only limits the potential strength of the connection but the stiffness too, due to the uneven glue thickness and applied pressing pressure during curing. Thus, there is notable scope of potential theoretical improvement of the tested glue properties which was evaluated through several alternative adhesive properties. These have been chosen by simply multiplying the current base case reference model (G1) by a factor of 2 (G2), 3 (G3) and 5 (G5) to determine its effect to the results. Figure 16 displays these results. The largest increase in performance is seen in G2 with its peak capacity now $10 \%$ higher. This is partly due to the relevant effects of increasing the glues stiffness but predominately due to the effects of a stronger bond due to increased cohesion. However, further increases of the glue properties practically has no effect. This is due to the adhesive becoming stronger than timber itself and thus the extra cohesion, particularly as seen in G3 and G5, not providing any 
additional improvement in performance. Rather, the increased stiffness of the glue is somewhat relevant although its effect at this stage is marginal at best.

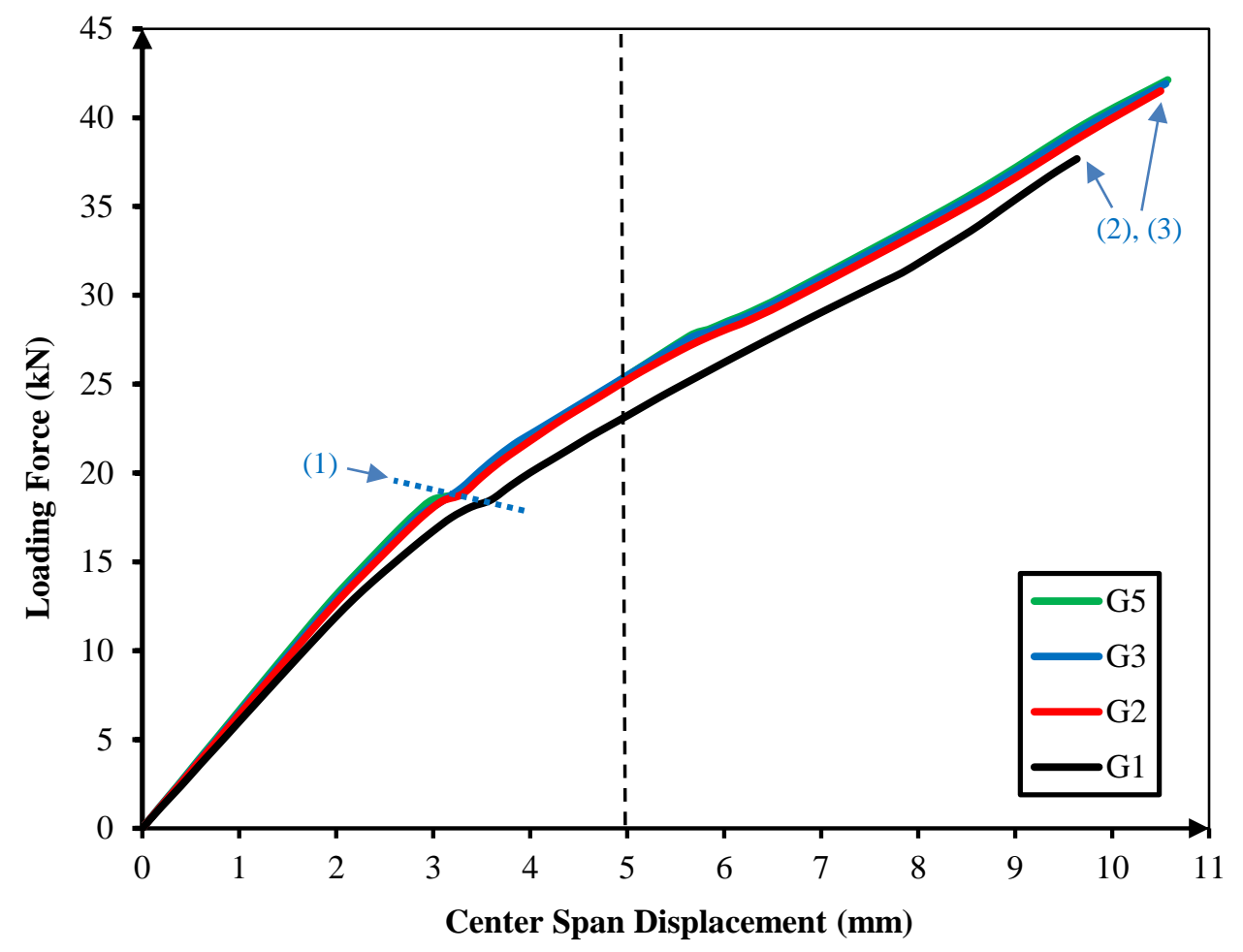

Figure 16. Force - deflection behaviour with modified glue parameters.

\subsection{Span to depth ratio}

Since this prefabricated system is designed for shorter spans such as corridors, it is important to note that across projects, the corridors are generally not all the same width. The ability for the chosen design to be manufactured repetitively at a constant overall depth in a high-volume prefabrication manufacturing line and accommodate various scenarios of span is important for efficiency, pre-made availability and economy of scale. Extreme scenarios of extra narrow and extra wide corridors have been looked at to determine the capacity and performance for multiple use of the chosen stressed-skin flooring cassette design for various spans. Figure $\mathbf{1 7}$ displays the force-deflection behaviour for the various spans with the key results summarised in Table 8. The long-dashed line that indicates the SLS limit is now not vertical but sloped. This is because the SLS limit changes for each of the cases, since the span is changed between each case. From the standard configuration which was tested experimentally, reducing the span to depth ratio by $33 \%$ increases the serviceability and ultimate load by $24 \%$ and $39 \%$ respectively. Whereas, increasing the span to depth ratio by $33 \%$, decreases the serviceability and ultimate load by $16 \%$ and $13 \%$ respectively. These results show the direct influence the span to depth ratio has on both the serviceability and ultimate limits. The large increase in ultimate load for the shorter span scenario with the same floor depth is likely influenced by direct load transfer to the supports. Onset of local buckling was captured through analysing stress distributions as per the prior outlined FEM method, 
particularly in the $1200 \mathrm{~mm}$ span scenario where the onset is not clear. Increasing the span to depth ratio delays the onset of local buckling primarily in terms of displacement. To delay the onset of local buckling to occur beyond the SLS limit the span to depth ratio is to be increased beyond the value of 8 .

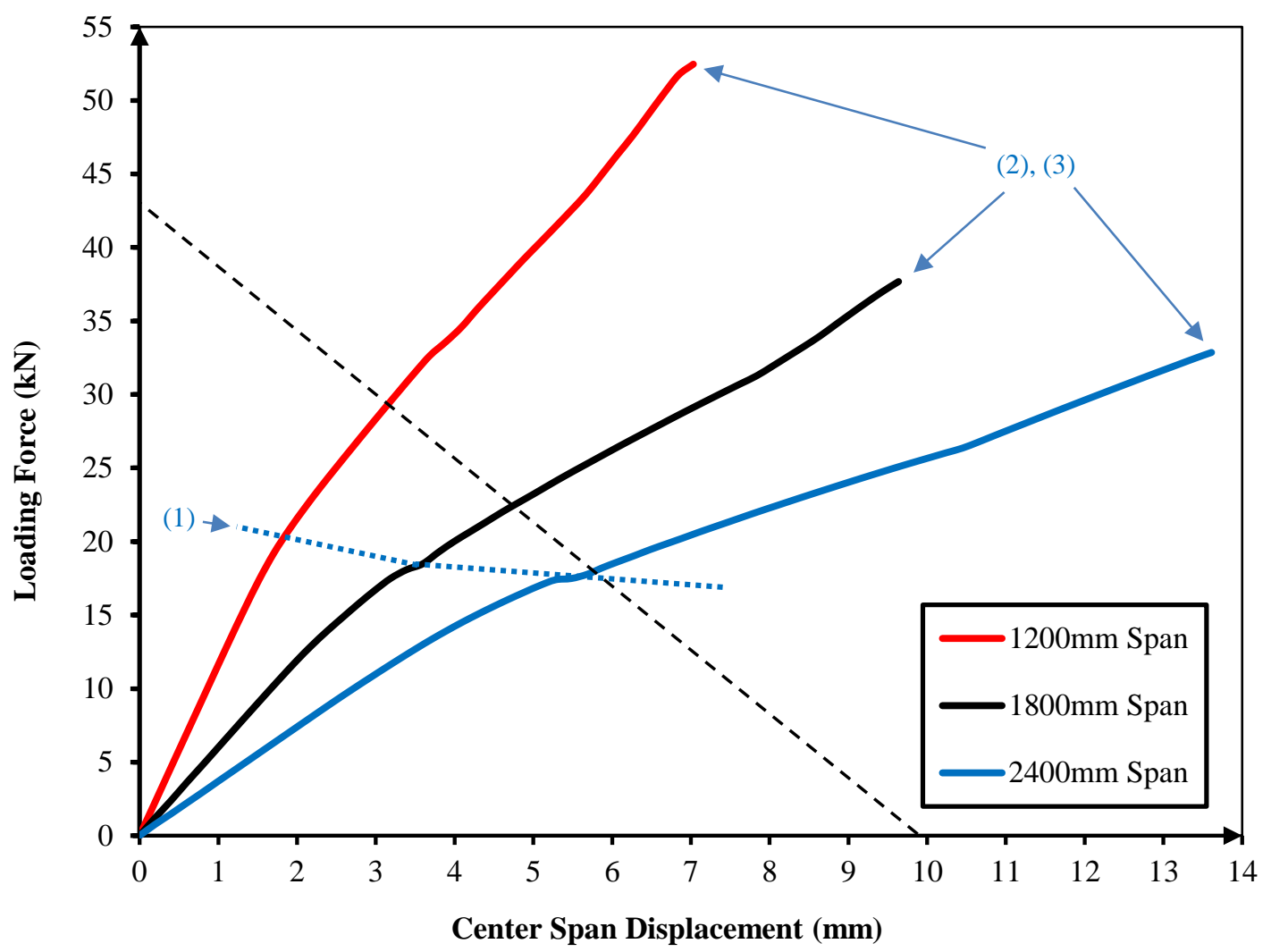

Figure 17. Force - deflection behaviour for alternative spans with constant overall depth of $300 \mathrm{~mm}$.

Table 8. Summary of the effects of span to depth ratio on performance.

\begin{tabular}{|c|c|c|c|c|}
\hline $\begin{array}{c}\text { Clear span } \\
(\mathbf{m m})\end{array}$ & $\begin{array}{c}\text { Span to depth } \\
\text { ratio }\left(\boldsymbol{L}_{\boldsymbol{c}} / \boldsymbol{D}\right)\end{array}$ & $\begin{array}{c}\text { Serviceability } \\
\text { load }(\mathbf{k N})\end{array}$ & $\begin{array}{c}\text { Ultimate load } \\
\text { capacity }(\mathbf{k N})\end{array}$ & $\begin{array}{c}\text { Displacement at } \\
\text { maximum load }(\mathbf{m m})\end{array}$ \\
\hline 1200 & 4 & 29.0 & 52.5 & 7.0 \\
1800 & 6 & 23.3 & 37.7 & 9.6 \\
2400 & 8 & 19.6 & 32.8 & 13.6 \\
\hline
\end{tabular}

\section{Conclusions}

Through the principles of reductive design, this study has investigated the removal of the dedicated top flange of engineered timber I-beams when used as cassettes. This prompted the use of the OSB flooring panel as a 'stressed-skin' structural member through an integrated glued connection to the web made possible through prefabrication and manufacturing in developing a material efficient timber floor cassette for short spans scenarios. A total of 20 stressed-skin specimens were tested with $150 \mathrm{~mm}$ and $300 \mathrm{~mm}$ nail spacings to understand its influence on the new connection and the corresponding structural behaviour, response and failure modes. This includes increasing the strength of the connection due to closer nail spacings. This provides a more uniform pressure and stronger hold for the glue during its curing, thus enabling a stronger connection and overall performance. It was found that the removal of the top flange and integration of the flooring panel has caused 
local buckling of the now stressed-skin to occur prior to other modes of failure. A detailed Finite Element Analysis (FEA) which takes into consideration the full behaviour of the materials, the glue and nail connections, along with failure modes has been validated and used to provide insight to potential design solutions. Key parameters that were investigated were the adhesive properties, the ratio of clear effective outstand width of the flange to the thickness of the stressed-skin $\left(b_{\text {eff,o }} / t\right)$, ratio of the clear depth of the web to the thickness of the web $\left(d_{p} / t_{w}\right)$, ratio of the clear span to the total depth of the composite beam $\left(L_{c} / D\right)$ and finally the spacing of the nails. This has resulted in a broad level understanding of the effects of these design parameters to the behaviour of stressed-skin engineered timber flooring cassettes.

The following key findings have been identified in this research:

1. A more material efficient flooring cassette can be achieved by directly chemically bonding the flooring panel to the web without any top flange to form stressed-skin member.

- However, local buckling of the skin is prone to occur prior to reaching the designed SLS limit.

2. Halving the nail spacing on average results in a $17 \%$ improvement in the ultimate load capability of stressed-skin engineered timber floor cassettes.

- This is due to the improved shear resistance and glued connection with closer nail spacing which provides a more uniform pressure distribution during the adhesives curing process.

3. Skin-slenderness ratio can be modified to delay the onset of local buckling beyond the serviceability limit.

- For the proposed system it is predicted that this is achieved when the skin slenderness ratio is reduced to 3.6 rather than 5.0. Practically this may be attained by using a $25 \mathrm{~mm}$ thick flooring panel rather than $18 \mathrm{~mm}$ for a $450 \mathrm{~mm}$ joist spacing.

4. Span to depth ratio can be increased to delay the onset of local buckling of the skin, particularly in terms of global displacement.

- It's predicted that a span to depth ratio beyond 8 will result in the SLS limit to be reached prior local buckling occurring due to reduced load per unit centre displacement.

5. Initial increases of the adhesives properties has greatest effect on capacity due to improved cohesion. This is limited once the glue becomes stronger than the timber itself.

- For the industrial manufacturing conditions and glue used, this can potentially amount to a $10 \%$ increase in peak capacity.

\section{Acknowledgements}

The author would like to acknowledge the generous support provided by the University of Melbourne, the Centre for Advanced Manufacturing of Prefabricated Housing (CAMP.H) and the Australian Research Council (Project ID: IC150100023).

\section{References}

1. Mirianon, F., S. Fortino, and T. Toratti, A method to model wood by using ABAQUS finite element software. Part 2. Application to dowel type connections. 2008, Espoo: Technical Research Centre of Finland, VTT Publication: Finland.

2. Orlowski, K., K. Shanaka, and P. Mendis, Manufacturing, Modeling, Implementation and Evaluation of a Weatherproof Seal for Prefabricated Construction. Buildings, 2018. 8(9 - Article 120). 
3. Orlowski, K., Assessment of Manufacturing Processes for Automated Timber-Based Panelised Prefabrication. Buildings, 2019. 9(5): p. 125.

4. $\quad$ Guss, L.M., Engineered wood products: the future is bright. Forest Products Journal, 1995. 45(7, 8): p. 17.

5. LI, M., et al., Modelling Of Timber I-beams In Bending. International Journal of Computational Methods and Experimental Measurements, 2017. 5(6): p. 821-833.

6. Islam, A., S.U. Nwokoli, and T. Debebe, Bearing capacity of I-joists. 2011.

7. Hindman, D., H.B. Manbeck, and J.J. Janowiak, Torsional rigidity of wood composite I-joists. Wood and fiber science, 2007. 37(2): p. 292-303.

8. Kozłowski, M., E. Serrano, and B. Enquist. Experimental investigation on timber-glass composite Ibeams. in Challenging Glass 4 \& COST Action TU0905 Final Conference. 2014. CRC Press.

9. Wang, S. and J.R. Cheng, Shear behaviour of OSB wood composite I-beams with web openings. Vol. 123. 1995: Canada-Alberta Partnership Agreement in Forestry.

10. Yeh, B., P.T.G. Williamson, and P.M.R. O'Halloran, Performance Standard Considerations for I-Joists used in Residential Floor Construction.

11. Shahnewaz, M., et al., STR-931: Timber I-Joists with Web Openings: Reinforcement, Capacity Prediction and Sensitivity Analysis. 2016.

12. ASTM-D5055, Standard Specification for Establishing and Monitoring Structural Capacities of Prefabricated Wood I-Joists. ASTM International, West Conshohocken, PA, 2016.

13. Weckendorf, J. Investigations of Dynamic Behaviour of Timber Floors. in Postgraduate Research Conference.

14. Yutang, J.J.L., Pure Aesthetics - Discuss on the Popularity of Minimalism Architecture. Huazhong Architecture, 2002. 3: p. 002.

15. Xue-song, W., Exploration of Contemporary Minimalism Architecture Design [J]. Journal of Chongqing Architecture University, 2004. 2: p. 004.

16. Dan, W., On minimalism interior design Shanxi Architecture, 2007. 7: p. 14.

17. Buchanan, A.H., Timber design guide. 3rd ed. ed. 2007, University of Canterbury New Zealand Timber Industry Federation.

18. Yang, J.H., L. Pham, and R. Leicester, Strength and stiffness of floor systems. 1994.

19. Gerber, C.D., Wood stressed-skin panels: an investigation into their behaviour, load distribution and composite properties. 2007.

20. Moody, R.C. and J.Y. Liu, Glued structural members. Wood handbook: wood as an engineering material. Madison, WI: USDA Forest Service, Forest Products Laboratory, 1999. General technical report FPL; GTR-113: Pages 11.1-11.24, 1999. 113.

21. Desler, H.F., Wood Structural Panels in Structural Components. APA Engineered Wood Handbook, The McGraw-Hill Companies Inc., New York (NY), USA, 2002.

22. $\quad$ Skog, K.E., et al., Wood products technology trends. J. of Forestry (Dec.), 1995: p. 30-33.

23. Bach, L., et al. Performance of Wood I-Joists Under Moderate Sustained Loading for 5 years. in 4th Structural Specialty Conference of the Canadian Society for Civil Engineering. Canada. 2002.

24. Thomas, W., Shear and flexural deflection equations for OSB floor decking with point load. European Journal of Wood and Wood Products, 2002. 60(3): p. 175-180.

25. Saliklis, E.P. and A.L. Mussen, Investigating the buckling behaviour of OSB panels. Wood and Fiber Science, 2000. 32(3): p. 259-268.

26. Lawson, R.M. and R.G. Ogden, 'Hybrid' light steel panel and modular systems. Thin-Walled Structures, 2008. 46(7): p. 720-730.

27. EN, EN 13986:2004+A1:2015 Wood-based panels for use in construction. Characteristics, evaluation of conformity and marking. European Engineering Standards, 2004: p. 72.

28. Egger EGGER OSB4 TOP - High Performance And Sustainability for elevated Wood Construction Requirements. EGGER Building Products GmbH, Weiberndorf 206380 St. Johann in Tirol, Austria, 2018.

29. Harvey, C.C., Wood Products New Zealand. ECOPLY® Specification \& Instalation Guide, 2015.

30. AS 1720.1, Timber structures Part 1: Design methods. 2010, Standards Australia Limited: Sydney, Australia. 
31. Energy, D.o.t.E.a., Your Home: Australia's Guide to Environmentally Sustainable Homes. Department of the Environment and Energy, 2015. 5th Edition

32. Kováčiková, J., et al., Finite element analysis of timber beams with flaws in ECCOMAS Congress 2016VII European Congress on Computational Methods in Applied Sciences and Engineering. 2016: Crete Island.

33. Portioli, F., et al., Numerical modeling of connections with timber pegs, in World Conference on Timber Engineering. 2010: Trentino, Italy.

34. Sandhaas, C. and J.W.G.v.d. Kuilen, Material model for wood HERON, 2013. 58(2/3): p. 171-191.

35. Thomas, W.H., Planar shear moduli of rigidity of an oriented strand board from bending and shear tests. Materials and Structures, 2004. 37(7): p. 480-484.

36. AS/NZS 2269.1, Plywood-Structural. Part 1: Determination of structural properties - Test methods. 2012, Standards Australia Limited/Standards New Zealand.

37. AS/NZS 4063.1, Characterization of structural timber. Part 1: Test methods. 2010, Standards Australia Limited/Standards New Zealand.

38. Plenzler, R., L. Ludwiczak-Niewiadomska, and P. Strzelecki, Elastic and strength properties of OSB layers/ Elasticnost i cvrstoc a slojeva OSB ploca. Drvna Industrija, 2017(1): p. 3.

39. Sika, Product Data Sheet: Sikaflex-221. 2013, Sika Australia Pty Ltd: Australia.

40. AS4364, AS 4364:2010: Timber-Bond performance of structural adhesives. Standards Australia, 2010.

41. Yeoh, D. and M. Fragiacomo, The design of a semi-prefabricated LVL-concrete composite floor. Advances in Civil Engineering, 2012. 2012.

42. Girhammar, U.A. and H. Andersson, Effect of Loading Rate on Nailed Timber Joint Capacity. Journal of Structural Engineering, 1988. 114(11): p. 2439-2456.

43. Scientific, C., Operators Manual. 815 West 1800 North Logan, Utah, 2016: p. 3-596.

44. AS/NZS1720, Timber structures - Design Method Standards Australia GPO Box 476, Sydney, NSW 2001, Australia., 2010.

45. VBA, Guide to Standards and Tolerances. Victorian Building Authority., 2015. 1.: p. 2-56. Goods Shed North 733 Bourke Street, Docklands Victoria, Australia 3008 GPO Box 536, Melbourne Victoria, Australia 3001.

46. Meghlat, E.M., et al., A new approach to model nailed and screwed timber joints using the finite element method. Construction and Building Materials, 2013. 41: p. 263-269.

47. Oktavianus, Y., et al., Structural behaviour of prefabricated load bearing braced composite timber wall system. Engineering Structures, 2018. 176: p. 555-568.

48. Song, K., C.G. Dávila, and C.A. Rose, Guidelines and Parameter Selection for the Simulation of Progressive Delamination, in 2008 Abaqus Users' Conference. 2008.

49. Zhu, E.C., et al., Buckling of oriented strand board webbed wood I-joists. Journal of Structural Engineering, 2005. 131(10).

50. Kamiya, F., Analytical studies on the nonlinear bending behavior of nailed layered components: part I. nailed layered beams. Wood and fiber science, 2007. 17(1): p. 117-131.

51. Qiu, L.P., E.C. Zhu, and J.W.G.v.d. Kuilen, Modeling crack propagation in wood by extended finite element method. European Journal of Wood and Wood Products, 2014. 72(2): p. 273-283.

52. $\mathrm{Xu}, \mathrm{J}$. and J.D. Dolan, Development of nailed wood joint element in ABAQUS. Journal of Structural Engineering, 2009. 135(8).

53. ABAQUS, ABAQUS CAE Documentaion Dassault Systèmes, ABAQUS Inc., 2017.

54. McKenzie, W.M. and H. Karpovich, The frictional behaviour of wood. Wood Science and Technology, 1968. 2(2): p. 139-152.

55. Fortino, S., et al., A simple approach for FEM simulation of Mode I cohesive crack growth in glued laminated timber under short-term loading. J Struct Mech, 2012. 45(1): p. 1-20.

56. Sandhaas, C., Mechanical behaviour of timber joints with slotted-in steel plates. 2012.

57. Janssens, S., Numerical modelling of dowelled connections in Laminated Veneer Lumber. 2017.

58. Ardalany, M., M. Fragiacomo, and P. Moss, Modeling of laminated veneer lumber beams with holes using cohesive elements. Journal of Structural Engineering, 2015. 142(1).

59. Ivanov, I.V., et al., Experimental and numerical investigation of plywood progressive failure in CT tests. Budownictwo i Architektura, 2008. 2: p. 79-94.

60. Ardalany, M., Analysis and design of laminated veneer lumber beams with holes. 2013. 
61. Danielsson, H., Perpendicular to grain fracture analysis of wooden structural elements-Models and applications. 2013.

62. Khelifa, M., et al., Finite element analysis of flexural strengthening of timber beams with Carbon FibreReinforced Polymers. Engineering Structures, 2015. 101: p. 364-375.

63. Keith Crews, R.S., Design Guide 31 - Timber Casset Floors. Wood Solutions - Design and Build, 2013.

64. Egger OSB3: The Professional choice for wood construction. EGGER Building Products GmbH, Weiberndorf 206380 St. Johann in Tirol, Austria, 2018.

65. Basler, K. and B. Thürlimann, Strength of plate girders in bending. 1960: Lehigh University, Fritz Engineering Laboratory.

66. Plywoods, A., Austral Marine Plywood. 1 Curzon St, Tennyson QLD 4105, 2018. 